MARA DELL'OSPEDALE RIBEIRO

DO TOPO PARA A BASE: ACONSELHAMENTO GENÉTICO EM

FAMÍLIAS A PARTIR DA SÍNDROME DE TREMOR/ATAXIA ASSOCIADA AO X FRÁGIL (FXTAS)

São Paulo

2017 
MARA DELL'OSPEDALE RIBEIRO

\section{DO TOPO PARA A BASE: ACONSELHAMENTO GENÉTICO EM FAMÍLIAS A PARTIR DA SÍNDROME DE TREMOR/ATAXIA ASSOCIADA AO X FRÁGIL (FXTAS)}

Dissertação apresentada ao Instituto de Biociências da Universidade de São Paulo para obtenção do título de Mestre em Ciências - Programa Mestrado Profissional em Aconselhamento Genético e Genômica Humana. Área de Concentração: Biologia (Genética)

Orientador: Prof. Dr. Fernando Kok

Coorientadora: Prof. ${ }^{a}$. Dra . Angela M. Vianna Morgante

São Paulo

2017 
Ribeiro, Mara Dell Ospedale

Do topo para a base: aconselhamento genético em famílias a partir da síndrome de tremor/ataxia associada ao X frágil (FXTAS) / Mara Dell Ospedale Ribeiro; orientador Fernando Kok. -- São Paulo, 2017.

$64 \mathrm{f}$.

Dissertação (Mestrado) - Instituto de Biociências da Universidade de São Paulo, Departamento de Genética e Biologia Evolutiva.

1. Síndrome de tremor/ataxia associada ao X frágil. 2. Gene FMR1. 3. Aconselhamento Genético. I. Kok, Fernando, orient. II. Título.

Catalogação da Publicação

Serviço de Biblioteca do Instituto de Biociências 
Nome: RIBEIRO, Mara Dell'Ospedale

Título: Do topo para a base: aconselhamento genético em famílias a partir da síndrome de tremor/ataxia associada ao X frágil (FXTAS)

Dissertação apresentada ao Instituto de Biociências da Universidade de São Paulo para obtenção do título de Mestre em Ciências - Programa Mestrado Profissional em Aconselhamento Genético e Genômica Humana.

Aprovado em:

Banca Examinadora

Prof. Dr.:

Instituição:

Julgamento:

Prof. Dr.:

Instituição:

Julgamento:

Prof. Dr.:

Instituição:

Julgamento: 


\section{DEDICATÓRIA}

À minha irmã, Marcela pela parceria de toda uma vida, e a meus pais, Marlene e Milton, por serem meus exemplos e sempre me apoiarem em minhas conquistas e realizações. 


\section{AGRADECIMENTOS}

Às duas famílias que participaram deste projeto, tornando-o possível.

Ao Prof. Dr. Fernando Kok, pela orientação e por acreditar na minha capacidade.

À Prof. a Dra. Angela M V Morgante, pela coorientação e confiança.

Ao corpo docente e aos funcionários da Universidade de São Paulo, pela estrutura de ensino.

Ao Instituto de Biociências, ao Departamento de Genética e Biologia Evolutiva, ao Laboratório de Genética Humana e ao Centro de Pesquisa sobre o Genoma Humano e Células-Tronco, por permitirem realizar as atividades do curso de mestrado.

À equipe de Neurogenética da Faculdade de Medicina da USP, em especial a Bruno, Fernanda, Clarissa e Isabella, pelo auxílio com os pacientes e pelo grande aprendizado que me proporcionaram nos ambulatórios. 


\section{RESUMO}

RIBEIRO, M. D. O. Do topo para a base: aconselhamento genético em famílias a partir da síndrome de tremor/ataxia associada ao $X$ frágil (FXTAS). 2017. 64 f. Dissertação (Mestrado em Aconselhamento Genético e Genômica Humana) - Instituto de Biociências, Universidade de São Paulo, São Paulo, 2017.

A Síndrome do $X$ frágil (SXF) é a forma mais comum de deficiência intelectual herdada. É causada por uma mutação no gene FMR1 (Fragile X Mental Retardation 1), que resulta na deficiência da proteína FMRP (Fragile $X$ Mental Retardation Protein). O gene FMR1, localizado no braço longo do cromossomo $X$, em Xq27.3, possui uma repetição de trinucleotídeos $(C G G)_{n}$ em sua região 5 ' não traduzida (região reguladora). Na população geral, o tamanho dessa repetição varia entre 5 a 44 trincas de bases. Uma expansão superior a 200 trinucleotídeos leva à hipermetilação e consequente silenciamento da transcrição do gene. Quando isso ocorre, tem-se uma mutação completa, a causa da SXF. Se a repetição expandida tem de 55 a 200 trincas de bases, chamada de pré-mutação, não ocorre hipermetilação e a proteína FMRP é produzida; portanto, a pré-mutação não está associada à SXF, porém está relacionada a outros quadros clínicos, particularmente à síndrome de tremor/ataxia associada ao X frágil (FXTAS; Fragile-X associated Tremor Ataxia Syndrome) e à insuficiência ovariana primária associada ao $X$ frágil (FXPOI; Fragile-X associated Primary Ovarian Insufficiency). $O$ objetivo deste trabalho foi investigar duas famílias cujos casos-índice foram encaminhados para o Centro de Pesquisa sobre o Genoma Humano e Células-Tronco para investigar ataxia espinocerebelar e nos quais a avaliação clínica e a história familial sugeriram a possibilidade de FXTAS; em ambos os pacientes, prémutação do gene $F M R 1$ foi detectada. Na Família 1, foi feito o diagnóstico de SXF em um neto da propósita e foi identificada a mutação completa em várias filhas e netas, todas com dificuldade de aprendizado. Na Família 2 não foram identificadas mutações completas e em um dos netos do propósito detectou-se mosaicismo de alelo intermediário e pré-mutação. Assim, diante da variada apresentação fenotípica, a possibilidade de condição associada ao gene FMR1 deve ser considerada frente aos fenótipos de deficiência intelectual, dificuldade de aprendizado, falência ovariana prematura e síndrome de tremor-ataxia. $O$ diagnóstico de FXTAS em famílias em que não há registro de SXF não é frequente, provavelmente diante do desconhecimento dessa possibilidade, mas tem importância fundamental para o aconselhamento genético, particularmente quanto à ocorrência de deficiência intelectual.

Palavras-chave: Síndrome de tremor/ataxia associada ao X frágil. Gene FMR1. Aconselhamento Genético. 


\section{ABSTRACT}

RIBEIRO, M. D. O. From top to bottom: genetic counseling in families ascertained through fragile X-associated tremor/ataxia syndrome (FXTAS) 2017. 64 f. Dissertação (Mestrado em Aconselhamento Genético e Genômica Humana) - Instituto de Biociências, Universidade de São Paulo, São Paulo, 2017.

Fragile $X$ syndrome (FXS) is the most common form of inherited intellectual disability. It is caused by a mutation in the Fragile $X$ Mental Retardation 1 (FMR1) gene located on the long arm of the $X$ chromosome at Xq27.3 that results in FMRP (Fragile X Mental Retardation Protein) deficiency. The FMR1 gene has a trinucleotide repeat $(C G G)_{n}$ at the $5^{\prime}$ untranslated region (regulatory region); in the general population, this repeat varies in size from 5 to 44 CGG triplets. An expanded repeat of more than 200 trinucleotides leads to hypermethylation and consequent silencing of the gene transcription - the full mutation that causes FXS. The repeat containing 55 to 200 triplets characterizes a premutation; there is no hypermethylation, the gene is transcribed, and the FMRP is produced; then premutations are not associated with FXS, but are related to other clinical conditions: Fragile X-associated Tremor/Ataxia Syndrome (FXTAS) and Fragile X-associated Primary Ovarian Insufficiency (FXPOI). The objective of this study was to investigate two families whose index cases were referred to the Centro de Pesquisa sobre o Genoma Humano e Células-Tronco to investigate spinocerebellar ataxia, whose clinical evaluation and family history suggested the possibility of FXTAS. Both probands were found to carry FMR1 premutations. In Family 1, the diagnosis of FXS was established in a grandson of the proband, and the full mutation was also identified in several of her daughters and granddaughters, all presenting with learning difficulties. In Family 2, no full mutations were detected; a proband's grandson had size mosaicism for FMR1 alleles, carrying an intermediate allele and a premutation. Although uncommon, possibly due to lack of knowledge about the syndrome, the diagnosis of FXTAS in families without FXS is important for genetic counseling, particularly regarding the occurrence of intellectual disability.

Key-words: Fragile X-associated Tremor/Ataxia Syndrome. FMR1 gene. Genetic counseling. 


\section{SUMÁRIO}

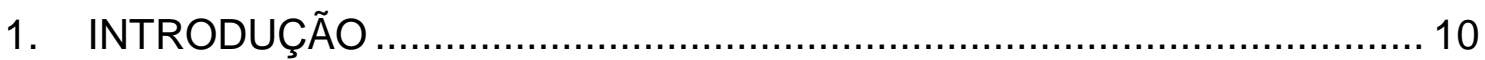

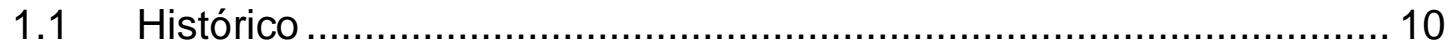

1.2 O Gene FMR1

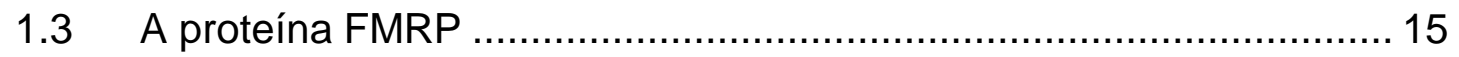

1.4 Características clínicas da síndrome do X Frágil ............................... 16

1.5 Fenótipos associados à pré-mutação do gene FMR1 ....................... 18

1.5.1 Síndrome de tremor/ataxia associada ao X frágil (FXTAS)......... 19

1.5.1.1 Características da FXTAS ................................................ 19

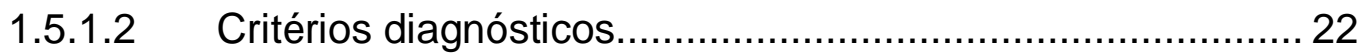

1.5.1.3 Patogênese da FXTAS ....................................................... 24

1.5.2 Insuficiência ovariana prematura associada ao X frágil (FXPOI) 26

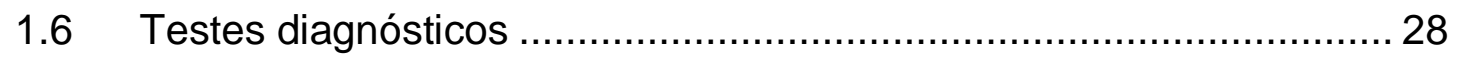

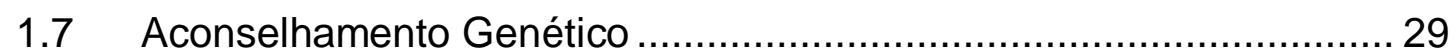

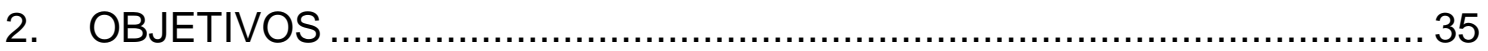

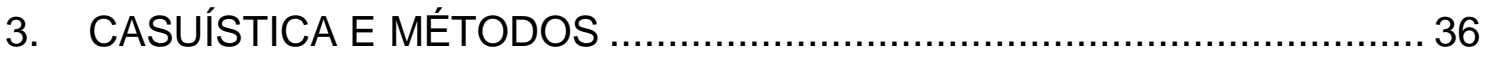

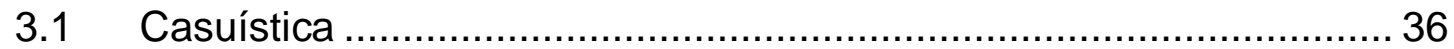

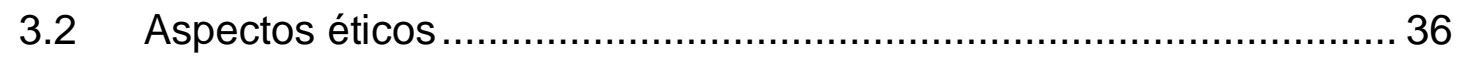

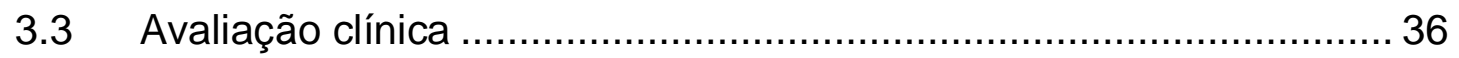

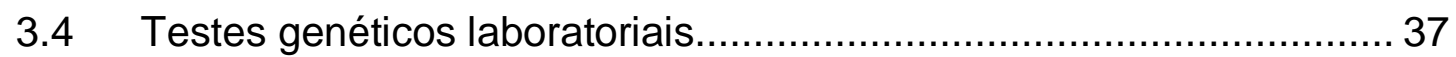

3.4.1 Teste molecular para a síndrome do X frágil ............................. 37

3.4.2 Análise cromossômica ............................................................... 37

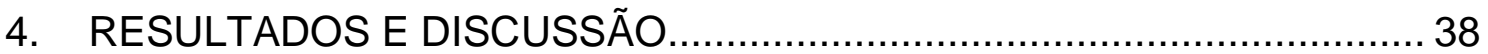

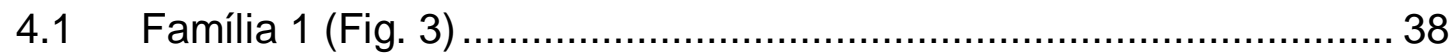

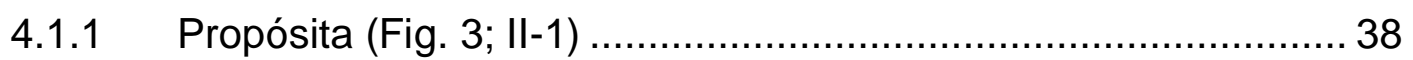

4.1.2 Primogênita da propósita (III-1) ............................................ 42

4.1.3 Neto da propósita (IV-4) ...................................................... 43

4.1.4 Demais indivíduos da família .................................................... 44

4.1.5 Aconselhamento genético para a Família 1 ............................... 44

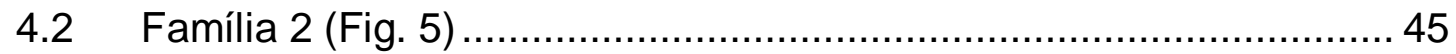

4.2.1 Propósito (Fig. 5; I-1) ........................................................ 45

4.2.2 Primogênita do propósito (II-1)............................................. 47

4.2.3 Netos do propósito (III-1 e III-3) ............................................. 47

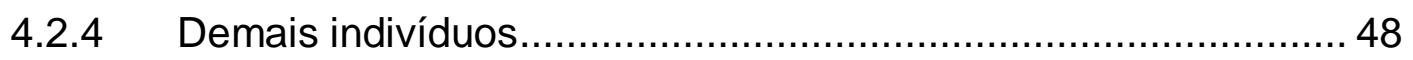

4.2.5 Aconselhamento genético para a Família 2 .............................. 48

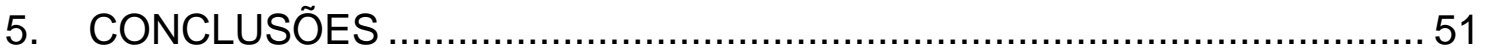




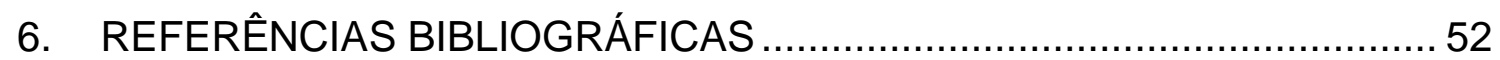

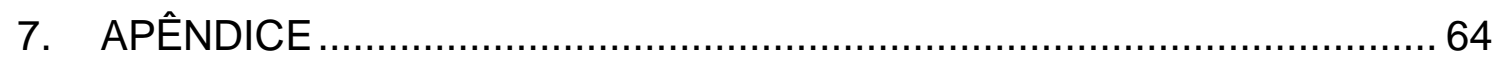

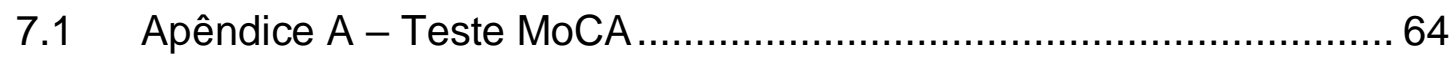




\section{INTRODUÇÃO}

\subsection{Histórico}

Em 1943, os pesquisadores J. Purdon Martin e Julia Bell descreveram uma família em que ocorriam homens com deficiência intelectual (DI), num padrão indicativo de herança ligada ao $X$ (Martin \& Bell, 1943). Posteriormente, vários trabalhos foram publicados descrevendo famílias semelhantes, quanto ao padrão de herança da DI (Renpenning et al., 1962; Opitz et al., 1965; Snyder \& Robinson; 1969), indicando que o cromossomo $X$ deveria conter vários genes contribuindo para a inteligência (Lehrke, 1972). Em 1969, H. A. Lubs descreveu uma família em que a DI tinha padrão de herança ligado ao X, e os indivíduos afetados apresentavam um sítio frágil na região distal do braço longo do cromossomo $\mathrm{X}$; esse cromossomo, que foi denominado $\mathrm{X}$ marcador, foi também detectado em algumas mulheres (Lubs, 1969). A segunda descrição do cromossomo marcador foi em uma família brasileira com DI ligada ao X (Escalante e Frota-Pessoa,1973; Vianna-Morgante et al., 1982). Estudos posteriores confirmaram a associação entre o sítio frágil no cromossomo X e DI (Giraud et al., 1976; Harvey et al., 1977; Sutherland, 1977a). Com a descoberta de que a manifestação do sítio frágil dependia das condições de cultura das células (Sutherland, 1977b), observou-se a associação do sítio frágil com DI, numa frequência maior do que antecipada (Sutherland \& Ashforth, 1979; Howard-Peebles \& Stoddard, 1980). Em 1981, Richards e col. detectaram o cromossomo $X$ frágil na família descrita por Martin e Bell e propuseram que a síndrome associada ao sítio frágil no cromossomo $X$ fosse denominada síndrome de Martin-Bell. A síndrome, entretanto, passou a ser conhecida como síndrome do $X$ frágil (SXF).

Algumas famílias com DI ligada ao $\mathrm{X}$, em que os afetados apresentavam macrorquidia, tinham sido descritas na época (Escalante et al., 1971; Turner et al., 1975; Cantú et al., 1978; Bowen et al., 1978). 
Turner e col. (1978), utilizando condições de cultura adequadas para a manifestação do sítio frágil, detectaram o $X$ frágil em famílias em que os indivíduos apresentavam DI associada a macrorquidia, com herança ligada ao $\mathrm{X}$, concluindo que se tratava de uma única síndrome. $\mathrm{Na}$ família brasileira descrita por Escalente e col (1971), o cromossomo X frágil também foi detectado (Vianna-Morgante et al., 1982).

Em 1991, foi possível esclarecer que a SXF é causada por mutação no gene FMR1 (Fragile $X$ Mental Retardation 1) localizado no cromossomo X, em Xq27.3 (Verkerk et al., 1991; Oberlé et al., 1991; Yu et al., 1991). Essa mutação silencia o gene, levando à ausência da proteína FMRP (Fragile X Mental Retardation Protein) (Pieretti et al., 1991).

\subsection{O Gene FMR1}

O gene FMR1 estende-se por aproximadamente $38 \mathrm{~kb}$, contém 17 exons e está altamente conservado entre as espécies (Verkerk et al., 1991; Oberlé et al., 1991; Yu et al., 1991). Possui uma repetição de trinucleotídeos $(C G G)_{n}$ em sua região 5 ' não traduzida (região reguladora), que na população geral varia de 6 a 44 trincas, os alelos mais comuns tendo repetições de 29 e 30 trinucleotídeos (Figura 1a). Os alelos na faixa normal são estáveis quando transmitidos entre as gerações, ou seja, não há variação no número de trincas de bases da repetição $(\mathrm{CGG})_{n}$.

A expansão da repetição superior a 200 trincas $(C G G)_{n}$ leva a sua hipermetilação e, consequentemente, ao silenciamento da transcrição e ausência da FMRP (Figura 1d). Quando isto ocorre, denomina-se a alteração de mutação completa, que é a causa da SXF. A mutação completa está presente em aproximadamente um em cada 4.000 a 7.000 homens e em uma em cada 8.000 a 11.000 mulheres (Hunter et al., 2014). 
A. Normal
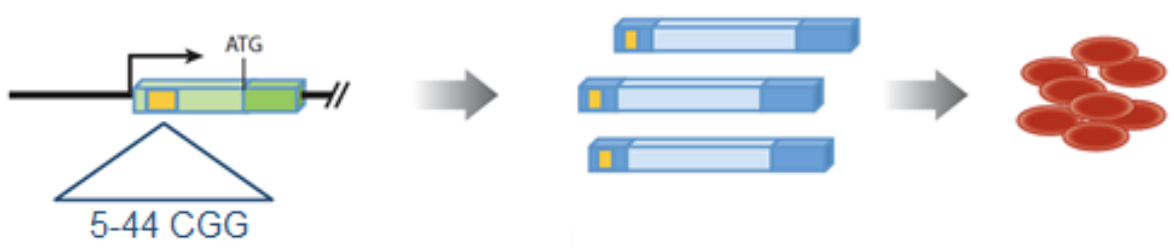

B. Intermediário
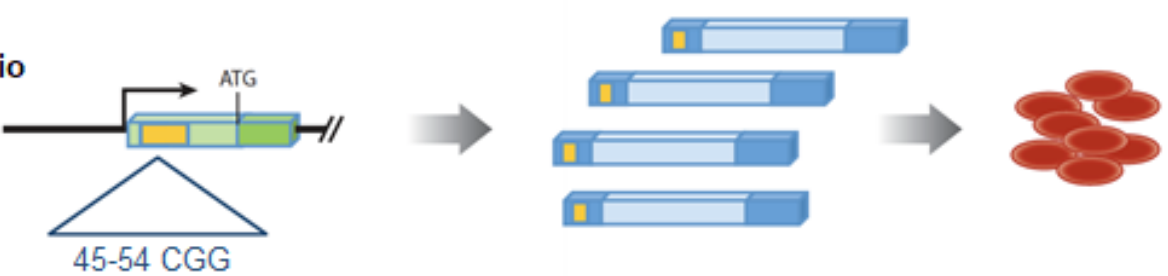

C. Pré-mutação

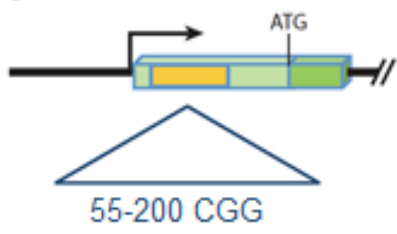

D. Mutação completa
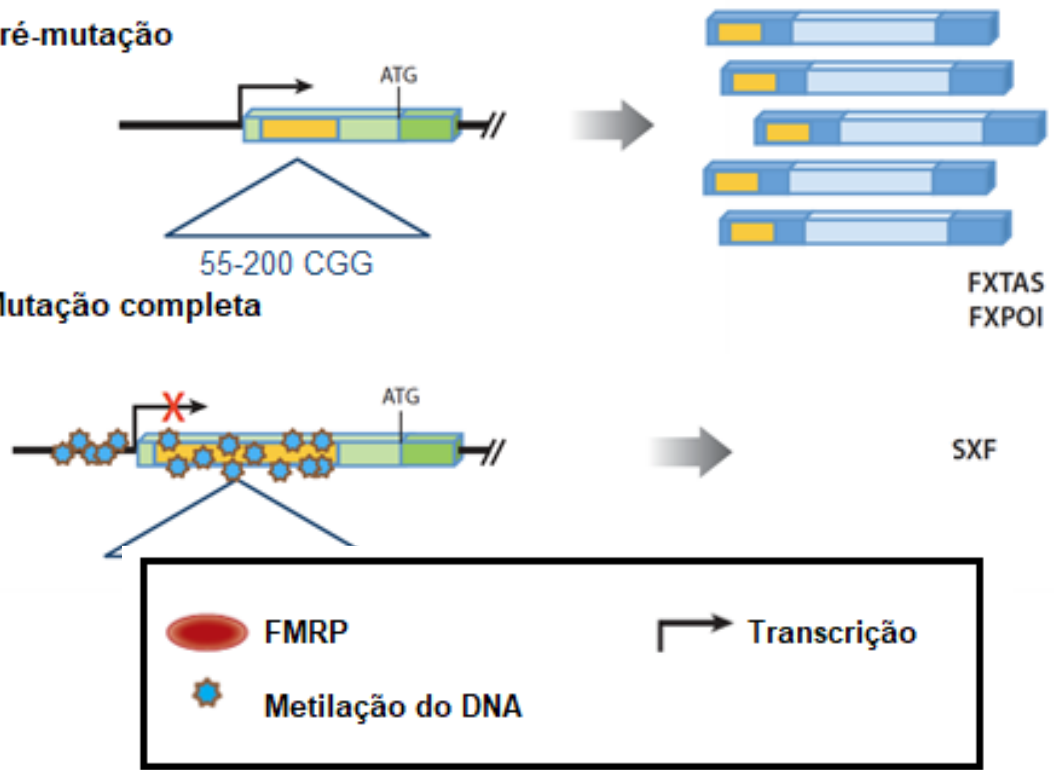

Figura 1: O gene FMR1: A. Alelo normal, desmetilado e com produção de níveis normais de RNAm e proteína; B. Alelo intermediário, também desmetilado e com produção de níveis normais de RNAm e proteína; C. Alelo pré-mutado, desmetilado e com produção aumentada de RNAm e diminuída da proteína; associado a FXTAS e FXPOI; D. Mutação completa, alelo metilado, não havendo produção do RNAm e da proteína, levando à SXF. Adaptado de Santoro et al. (2012). 
Quando o número de repetições (CGG) $)_{n}$ se situa entre 55 e 200 trinucleotídeos tem-se uma pré-mutação, caracterizada por ser instável na transmissão, podendo ter aumento do número de repetições de uma geração para outra (Figura 1c). Nos alelos na faixa de pré-mutação não ocorre hipermetilação, a proteína FMRP é produzida (Devys et al., 1993) e não ocorrem os sinais clínicos característicos da síndrome do $\mathrm{X}$ frágil. No entanto, a pré-mutação foi relacionada a outros quadros clínicos, especialmente a síndrome de tremor/ataxia associada ao $\mathrm{X}$ frágil (FXTAS; Fragile $\boldsymbol{X}$-associated Tremor/Ataxia Syndrome) e a insuficiência ovariana prematura associada ao X frágil (FXPOI; Fragile $\boldsymbol{X}$ associated Primary Ovarian Insufficiency). Diversos estudos mostram também a relação entre a pré-mutação e outras condições, tais como déficit de atenção, hiperatividade e fobia social (Cornish et al., 2005; Farzin et al., 2006). A prevalência estimada da pré-mutação na população geral é de uma entre 150-300 mulheres e um entre 400-850 homens (Hunter et al., 2014).

Há ainda uma quarta classe de alelos - intermediários ou gray-zone, caracterizados pela repetição no intervalo entre 45 e 54 trincas, e que podem ou não se expandir ao serem transmitidos (Figura 1b). Apesar de poderem ser instáveis, não há relato de alelos intermediários que se tenham expandido para mutação completa em uma geração (Nolin et al., 2003).

Apesar de a mutação completa ser estável quando metilada nos tecidos adultos (Wöhrle et al., 1993), durante a embriogênese, quando a metilação ainda não foi completamente estabelecida, as repetições podem apresentar instabilidade durante as mitoses e levar a mosaicismo quanto ao tamanho da expansão da repetição (CGG)n (Wöhrle et al., 2001): mosaicismo de mutação completa e pré-mutação (MoMP; Mosaicism for full Mutation and Premutation); mosaicismo de mutação completa e alelo normal (MoMN; Mosaicism for full Mutation and Normal alleles); mosaicismo de mutação completa, pré-mutação e alelo normal (MoMPN; Mosaicism for full Mutaition, Premutation and Normal alleles).

Há também o mosaicismo de metilação (MoMe; Mosaicism for Methylation), quando o indivíduo apresenta alelo com repetições maiores 
que 200 trincas que, em algumas células, está completa ou parcialmente desmetilado. Esses indivíduos podem apresentar um fenótipo moderado da SXF ou normal (homens altamente funcionais com SXF) (Hagerman et al., 1994; Tassone et al., 2000a).

Os processos mutacionais que levam à expansão da repetição dos alelos normais do gene $F M R 1$ para a mutação completa são complexos. Porém, algumas características já são bem conhecidas: não há descrição de alelos normais que tenham expandido diretamente para mutação completa e o risco de expansão da pré-mutação para mutação completa depende do tamanho da repetição (CGG) (Heitz et al., 1992; Ashley-Koch et al., 1998). No entanto, é importante ressaltar que expansões e contrações da repetição podem ocorrer mesmo em alelos normais (Finucane et al., 2012).

Há também um elemento que contribui para a estabilidade da repetição: as interrupções das trincas $C G G$ por AGG na repetição $(C G G)_{n}$. As primeiras descrições dessas interrupções foram na década de 90 (Eichler et al., 1994; Kunst \& Warren, 1994; Snow et al., 1994; Zhong et al., 1995). Tipicamente, as interrupções AGG estão separadas por nove a 11 repetições CGG. (Eichler et al., 1994). Nos alelos normais, há entre duas e quatro interrupções AGG, enquanto que a maioria das pré-mutações possuem duas interrupções ou nenhuma (Eichler et al., 1994; Crawford et al., 2000). As trincas AGG diminuem o risco de escorregamento da DNA polimerase e, portanto, de expansão (Gacy et al., 1995).

Além da expansão da repetição $(C G G)_{n}$, outras variantes, incluindo mutações de ponto e deleções, já foram descritas como causa de SXF, em estudos de casos (revisão em Grønskov et al., 2011). Collins et al. (2010a) sequenciaram o gene FMR1 em 963 indivíduos do sexo masculino com atraso de desenvolvimento, que não tinham mutação completa; detectaram uma mutação missense em região conservada do gene e três mutações no promotor, estas levando a redução significativa nos níveis da proteína. $\mathrm{Na}$ análise do gene $F M R 1$, por sequenciamento baseado em array, em 51 pacientes com quadro sugestivo de SXF, mas negativos para a mutação completa, Collins et al. (2010b) detectaram 
uma deleção; concluíram que variantes de sequência no gene FMR1 não parecem ser causa significativa de SXF, mas sugeriram que a investigação de deleções pode ser de utilidade clínica.

\subsection{A proteína FMRP}

Em 1993, a proteína FMRP (Fragile Mental Retardation Protein) foi caracterizada (Devys et al., 1993, Verheij et al., 1993). Hoje se sabe do seu papel na plasticidade sináptica, mecanismo importante para aprendizado e memória. A FMRP está conservada entre as espécies e, nos humanos, existem diversos sítios alternativos de splicing; cerca de 20 diferentes proteínas são formadas (Brackett et al., 2013), sendo a proteína de 71-kDa a principal isoforma produzida (Ashley et al., 1993).

A FMRP é amplamente expressa nos tecidos, principalmente em cérebro, testículos e ovários (Devys et al., 1993, Hinds et al., 1993; Kaufmann et al., 2002). É uma proteína de ligação ao RNAm e é capaz de reconhecer tanto RNA codificadores quanto não codificadores (Ashley et al., 1993; Siomi et al., 1993; O'Donnel \& Warren, 2002) entre estes, microRNAs (Edbauer et al., 2010; Gessert et al., 2010). Estima-se que a FMRP se ligue a aproximadamente $4 \%$ dos RNAm no cérebro (Ashley et al., 1993). Sua principal função é no desenvolvimento e na regulação da plasticidade sináptica. Ela se localiza nos espaços póssinápticos das espinhas dendítricas, onde se liga e reprime a tradução de um subconjunto alvo de RNAm dendítricos; após a recepção de sinais sinápticos apropriados, a FMRP permite a síntese de proteínas chave da plasticidade sináptica. $\mathrm{Na}$ ausência da FMRP, há síntese excessiva de proteínas, associada ao crescimento alterado das espinhas dendríticas (Santoro et al., 2012).

Estudos realizados com modelos funcionais mostraram que a FMRP penetra no núcleo onde se liga a RNAm alvos e os acompanha ao citoplasma (Eberhart et al., 1996). Dentre os RNAm alvos da FMRP, 28 são de genes candidatos de transtorno do espectro autista (TEA) (Darnell et al., 2011). 


\subsection{Características clínicas da síndrome do X Frágil}

O quadro clínico dos homens com a SXF é mais grave do que o das mulheres portadoras de mutação completa, pois eles apresentam a mutação em hemizigose, enquanto as mulheres possuem um alelo para produção normal de FMRP. Indivíduos do sexo masculino com SXF apresentam deficiência intelectual de moderada a grave $e$ frequentemente manifestam comportamento do transtorno do espectro autista (Harris et al., 2008). As características comportamentais são típicas e contribuem para o diagnóstico, entre elas: déficit de atenção, hiperatividade, fala repetitiva, contato visual pobre, resistência ao contato físico e hábito de abanar e morder as mãos (Tabela 1; Hagerman et al., 2002).

A SXF é a forma mais comum de deficiência intelectual herdada, e, assim, o padrão de conduta é considerar a realização do teste para a SXF em crianças que apresentam deficiência intelectual de causa desconhecida ou autismo (Garber et al., 2008).

Em relação às características físicas, há grande variabilidade, principalmente em crianças pequenas. Destacam-se como características físicas: face alongada, orelhas grandes e proeminentes, palato alto, hiperextensibilidade articular, prolapso da válvula mitral, macrorquidia (após a puberdade) e pés planos (Tabela 1; Hagerman et al., 2002). 
Tabela 1: Características clínicas da Síndrome do X frágil

\begin{tabular}{cc}
\hline \multicolumn{2}{c}{ Características físicas } \\
\hline Frequência $>45 \%$ & \\
\hline Macrorquidia (após a puberdade) & $74 \%$ \\
Face alongada & $74 \%$ \\
Orelhas grandes e/ou proeminentes & $66 \%$ \\
Pés planos & $65 \%$ \\
Hiperextensibilidade articular & $64 \%$ \\
Palato alto & $48 \%$ \\
Calos nas mãos & $45 \%$ \\
\hline Frequência <45\% & \\
\hline Pectus excavatum & $43 \%$ \\
Polegares trifalângicos & $41 \%$ \\
Prega palmar única & $35 \%$ \\
Estrabismo & $33 \%$ \\
Mandíbula proeminente & $28 \%$ \\
Escoliose & $20 \%$ \\
\hline Características comportamentais & \\
\hline Fala repetitiva & $91 \%$ \\
Contato visual pobre & $87 \%$ \\
Resistência ao contato físico & $74 \%$ \\
Hiperatividade & $74 \%$ \\
Morder as mãos & $56 \%$ \\
\hline
\end{tabular}

Adaptada de Hagerman, 2002.

As mulheres portadoras de mutação completa apresentam, em geral, quadro clínico mais leve do que o dos homens, mas a inativação aleatória do cromossomo $X$ pode fazer com que haja variação na gravidade do quadro clínico, e elas podem apresentar desde dificuldade de aprendizagem leve até deficiência intelectual. Estima-se que cerca de metade das mulheres com mutação completa apresentem sinais da SXF (Sherman et al., 2005). Aproximadamente $71 \%$ das mulheres com mutação completa apresentam QI abaixo de 85 , o que caracteriza 0 limite de deficiência intelectual moderada/leve (de Vries et al., 1996). No entanto, aquelas com QI normal muitas vezes têm dificuldade de aprendizado significativa e/ou distúrbios psicológicos e 
comportamentais. As características físicas da SXF são encontradas com menos frequência nas mulheres que nos homens, apenas $28 \%$ apresentam face alongada e mandíbula proeminente (Fryns et al., 1986), cerca de $40 \%$ possuem hiperextensibilidade articular e $19 \%$ pés planos (Loesch \& Hay, 1988), sendo as orelhas grandes e proeminentes a principal característica identificada nas mulheres com SXF (Hagerman et al., 1992).

Estudos já associaram a SXF com epilepsia e concluíram que as crianças com SXF possuem risco aumentado de ter convulsões, documentadas em 13 a $18 \%$ dos meninos e em $5 \%$ das meninas com mutação completa (Hagerman et al., 2002).

\subsection{Fenótipos associados à pré-mutação do gene FMR1}

Estudos em famílias com SXF evidenciaram a presença de sinais clínicos nos indivíduos portadores de pré-mutação diferentes daqueles encontrados nos portadores de mutação completa. As duas condições mais bem estabelecidas são a insuficiência ovariana prematura associada ao $\boldsymbol{X}$ frágil (FXPOI; Fragile- $\boldsymbol{X}$ associated Primary Ovarian Insufficiency) e a síndrome de tremor/ataxia associada ao $X$ frágil (FXTAS; Fragile-X associated Tremor/Ataxia Syndrome), que serão descritas abaixo.

Existem artigos que descrevem a manifestação de outros fenótipos clínicos nos portadores de pré-mutação que, no entanto, ainda não estão bem caracterizados: ansiedade (Bourgeois, 2011; Roberts et al., 2009; Hall, 2016; Cordeiro et al., 2015), transtorno obsessivocompulsivo (Cordeiro et al., 2015; Hessl et al., 2005; Schneider et al., 2016), depressão (Bourgeois, 2011; Roberts et al., 2009; Seritan et al., 2013), doenças da tireoide (Coffey et al., 2008; Winarni et al., 2012; Rodriguez-Revenga et al., 2009), arritmias cardíacas e hipertensão (Hamlin et al., 2012, Coffey et al., 2008), enxaquecas (Hall, 2016; Au, 2013), fibromialgia (Coffey et al., 2008; Winarni et al., 2012; Leehey et al., 2011), distúrbios do sono (Chonchaiya et al., 2010; Summers et al., 
2014), apneia do sono (Hamlin et al., 2011), síndrome das pernas inquietas (Summers et al., 2014) e neuropatias (Hagerman et al., 2007b). Também há relato de autismo em $10 \%$ dos meninos com pré-mutação, déficit de atenção e hiperatividade (Farzin et al., 2006) e nos adultos, déficit e fobia social (Cordeiro et al., 2015).

\subsubsection{Síndrome de tremor/ataxia associada ao X frágil (FXTAS)}

A FXTAS foi identificada em 2001 pelo grupo da Dra. Randi J. Hagerman (Hagerman et al., 2001), quando acompanhava famílias com SXF no Fragile $X$ Clinic and Research Program, no hospital infantil em Denver, e observou o quadro de tremor progressivo, ataxia e declínio cognitivo em avôs de crianças com SXF (Hall et al., 2012a).

A FXTAS é uma doença neurodegenerativa, de início tardio, progressiva e que afeta os movimentos e vem muitas vezes acompanhada de declínio cognitivo. O risco de portadores de prémutação apresentarem FXTAS é de cerca de $8-16 \%$, para as mulheres e de $40-45 \%$, para os homens (Greco et al., 2008). A penetrância está relacionada ao tamanho da repetição $(C G G)_{n}$ e à idade do paciente (Jacquemont et al. 2004b). Na faixa de pré-mutação, há um aumento de cerca de 2-8 vezes nos níveis de RNAm do gene FMR1, quando comparados com os níveis de RNAm na faixa do alelo normal (Tassone et al., 2000b), o que, acredita-se ser tóxico para os neurônios, sendo causa da FXTAS.

\subsubsection{Características da FXTAS}

Após a primeira descrição da FXTAS diversos estudos foram conduzidos, caracterizando a síndrome (revisão em Capelli et al., 2010).

Constituem características principais da FXTAS:

a) Tremor intencional progressivo: é o tremor cinético, observado durante a realização de movimentos intencionais e que prejudica a realização de tarefas diárias como comer, escrever e segurar objetos. O tremor afeta principalmente os membros superiores 
levando a incapacidade que pode ser de moderada a grave (Jacquemont et al., 2003, 2004a);

b) Ataxia da marcha: é o comprometimento da coordenação dos movimentos ao caminhar. Na FXTAS a marcha possui base alargada, os pacientes também apresentam quedas frequentes e não são capazes de realizar a marcha em tandem (Jacquemont et al., 2004a; Rogers et al., 2003);

c) Declínio cognitivo: é observado diminuição do controle da atenção, do funcionamento executivo e do aprendizado, porém há relativa preservação da linguagem e das habilidades visuais e espaciais. Também pode ser percebida alteração de humor e de comportamento, como depressão, mudanças repentinas de humor, comportamento inadequado ou recluso, desinibição, ansiedade e demência (Jacquemont et al., 2003, 2004a);

d) Parkinsonismo: é a lentidão na realização dos movimentos que também ficam mais rígidos; observa-se o tremor de descanso, que é o tremor estático que ocorre quando se está em repouso (Jacquemont et al., 2004a; Hall et al., 2009);

e) Neuropatia periférica: atinge os membros inferiores e é definida pela diminuição ou perda total dos reflexos tendinosos, redução da sensibilidade ao toque, formigamento, dor nas extremidades e fraqueza muscular na região proximal dos membros inferiores (Hagerman et al., 2004, 2007b; Jacquemont et al., 2004a);

f) Disfunções autonômicas: as principais são incontinência urinária, incontinência intestinal e impotência (Jacquemont et al., 2004a).

Além das manifestações clínicas, sinais radiológicos e neuropatológicos são importantes para 0 estabelecimento do diagnóstico. A FXTAS é classificada como uma doença da substância branca, pois em exames de imagem de ressonância magnética observase um padrão cerebral anormal, afetando regiões periventriculares e subcorticais cerebrais. O principal achado radiológico é a hiperintensidade do pedúnculo cerebelar médio, conhecido como sinal do Pedúnculo Cerebelar Médio (MCP; Middle Cerebellar Peduncle) visto em T2 (Brunberg et al., 2002; Jacquemont et al., 2003) e que está 
presente em $60 \%$ dos homens afetados e em $13 \%$ das mulheres afetadas (Brunberg et al., 2002; Adams et al., 2007).

Outros sinais em ressonância magnética são: hiperintensidade no esplênio do corpo caloso (Hall et al., 2014); hiperintensidade na ponte, ínsula e na substância branca periventricular e atrofia generalizada no cérebro e cerebelo (Muzar et al., 2014a). Um estudo revelou a presença de hiperintensidade no esplênio do corpo caloso, em $50 \%$ dos pacientes com FXTAS (Apartis et al., 2012). Nas mulheres, esses sinais radiológicos foram mais comuns do que o sinal de $\mathrm{MCP}$, porém não são específicos de FXTAS, o que pode acabar dificultando a definição do diagnóstico.

Em 2002, Greco e colaboradores realizaram análise de amostras do cérebro de quatro idosos portadores de pré-mutação, que faleceram com sinais clínicos de FXTAS, o que resultou na primeira descrição de um novo achado neuropatológico em FXTAS: as inclusões intranucleares. Essas inclusões estavam presentes nos neurônios e nos astrócitos, no cérebro dos quatro indivíduos do estudo, bem delimitadas, eosinófilas e ubiquitino-positivas, não tendo sido encontradas nas células de Purkinje; também foi observada a formação de espongioses na substância branca profunda, o que é consistente com os achados em imagem de ressonância magnética (Greco et al., 2002). Em estudo subsequente (Greco et al., 2006), foi realizada a análise pós-morte de amostras de cérebro e medula espinhal, em outros 11 indivíduos com diagnóstico de FXTAS. Os resultados foram condizentes com os da pesquisa anterior, e concluiu-se que o número de inclusões intranucleares encontradas no SNC está diretamente correlacionado com o tamanho da pré-mutação; a correlação é inversamente proporcional, quando comparada a quantidade de inclusões com a idade de início de FXTAS e a idade de óbito. Um estudo, realizado em 2011 por Hunsaker e colaboradores, descreveu a formação das inclusões intranucleares em outros tecidos, entre eles, sistema nervoso periférico, músculo cardíaco, esôfago, testículos, tireoide, glândula adrenal e glândula pituitária (Hunsaker et al., 2011). Esse achado ajuda a entender outros sintomas associados a 
FXTAS, como arritmia cardíaca, neuropatia, hipertensão e problemas de deglutição.

As primeiras descrições de FXTAS em mulheres foram feitas em 2004 e, das quatro participantes do estudo, apenas uma apresentou as inclusões intranucleares típicas (Hagerman et al., 2004). Um estudo posterior sobre os achados radiológicos nas mulheres com FXTAS revelou atrofia e doença de substância branca menos extensa do que aquelas encontradas nos homens (Adams et al., 2007); mostrou também que a frequência de demência entre as mulheres com FXTAS é menor que nos homens - entre os 68 participantes do estudo (50 homens e 18 mulheres), $50 \%$ dos homens desenvolveram demência, mas nenhuma das mulheres.

Estudos mais recentes evidenciam novas características da FXTAS. Fraint e col. (2014) encontraram alterações oftalmológicas, incluindo nistagmo optocinético, visão vertical prejudicada e sacadas lentas, ao examinar 19 indivíduos com FXTAS, incluindo sete mulheres. Também foi observado que dois desses pacientes apresentavam características de paralisia supranuclear progressiva (PSP), outros cinco tinham fenótipo PSP-like, levando à conclusão de que, provavelmente, a prémutação contribui para o desenvolvimento de PSP e de outras doenças do desenvolvimento. A doença de substância branca pode ocorrer em outras regiões que não a periventricular e no sinal de MCP, tendo sido relatadas alterações na base da ponte (Loesch et al., 2011), no esplênio e no genu do corpo caloso (Apartis et al., 2012) e na ínsula (Hagerman \& Hagerman, 2013). Foi observado que a hiperintensidade do corpo caloso está presente em aproximadamente $50 \%$ dos indivíduos com FXTAS (Apartis et al., 2012).

\subsubsection{Critérios diagnósticos}

Jacquemont e et al. (2003) estabeleceram critérios diagnósticos para FXTAS. Eles propuseram três categorias de diagnóstico: "definitivo", 
"provável" e "possível", cada classe caracterizada pela combinação de sinais e sintomas clínicos, radiológicos e patológicos.

Os sinais e sintomas clínicos e radiológicos foram classificados como "principais" e "secundários". Assim, na categoria de diagnóstico "definitivo" é necessária a presença de um sinal radiológico principal e um sinal clínico principal ou um sinal clínico principal e a presença de inclusões intranucleares (pós-morte); na categoria "provável", devem estar presentes um sinal radiológico principal e um sinal clínico secundário ou dois sinais clínicos principais; já na categoria "possível" é essencial a presença de um sinal clínico principal e um sinal radiológico secundário (Tabela 2; pág. 24).

A presença de pré-mutação no gene $F M R 1$ é exigência para se estabelecer o diagnóstico de FXTAS, pois é ela quem diferencia a FXTAS de outras doenças neurodegenerativas idiopáticas. No entanto, a FXTAS já foi diagnosticada em pacientes portadores de alelo intermediário (Hall et al., 2012b), em indivíduos com a mutação completa, não metilada e em indivíduos com mosaicismo de tamanho de alelos de FMR1 (Loesch et al., 2012). Esses casos, em que a expansão da repetição $(C G G)_{n}$ não está nos limites de pré-mutação, levou à inclusão, nos critérios diagnósticos, de alelos intermediários e de mutação completa não metilada, em que há aumento na expressão do RNAm do FMR1 (Hall et al., 2014). 
Tabela 2: Critérios diagnóstico para FXTAS

\begin{tabular}{ccl}
\hline & \multicolumn{2}{c}{ Critérios } \\
\hline \multirow{2}{*}{ Diagnóstico } & $\begin{array}{l}\text { Um sinal clínico principal + um sinal } \\
\text { radiológico principal } \\
\text { Um sinal clínico principal + inclusões } \\
\text { intranucleares (pós-morte) }\end{array}$ \\
\cline { 2 - 3 } & Provável & $\begin{array}{l}\text { Dois sinais clínicos principais } \\
\text { Um sinal clínico secundário + um sinal } \\
\text { clínico radiológico principal }\end{array}$ \\
\cline { 2 - 3 } Clínico & Possível & $\begin{array}{l}\text { Um sinal clínico principal + um sinal } \\
\text { radiológico secundário }\end{array}$ \\
\cline { 2 - 3 } & Sinais e sintomas \\
\cline { 2 - 3 } Radiológico & Secundário & $\begin{array}{l}\text { Parkinsonismo, déficit moderado a } \\
\text { severo na memória de curto prazo e } \\
\text { déficit na função executiva }\end{array}$ \\
\cline { 2 - 3 } & Principal & $\begin{array}{l}\text { RM: lesões na substância branca no } \\
\text { pedúnculo cerebelar médio (sinal MCP) }\end{array}$ \\
\cline { 2 - 3 } & Secundário & $\begin{array}{l}\text { RM: lesões na substância branca } \\
\text { cerebral, atrofia cerebral generalizada de } \\
\text { moderada a grave }\end{array}$ \\
\hline
\end{tabular}

Adaptado de Capelli et al., 2010

\subsubsection{Patogênese da FXTAS}

A patogênese da FXTAS ainda não foi bem estabelecida, porém vários mecanismos foram propostos baseados nos elevados níveis de RNAm associados à pré-mutação, todos eles envolvendo ganho de função tóxico do RNAm.

O primeiro mecanismo proposto propõe a ligação aumentada de proteínas à repetição $(\mathrm{CGG})_{\mathrm{n}}$ expandida, bloqueando as funções celulares normais dessas proteínas (Hagerman, 2012). Esse modelo é baseado no paradigma da distrofia miotônica, em que a expansão da repetição CUG na 3'UTR no RNAm do gene DMPK sequestra um modulador de splicing, bloqueando seu papel e levando, assim, à distrofia miotônica 1 (doença de Steinert) (Timchenko, 2013). Já na FXTAS, ainda não se sabe com clareza quais proteínas são sequestradas, mas há algumas candidatas, com base na evidência da 
ligação ao RNA com a expansão, in vitro e in vivo (Hagerman \& Hagerman, 2016): hnRNP A2/B1; pura; Sam68; e DGCR8-Drosha, associada, quando sequestrada, a diminuição dos níveis de vários microRNA e o consequente aumento de seus precursores, nos tecidos cerebrais de indivíduos com FXTAS (Sellier et al., 2013).

O segundo modelo envolve a tradução do RNAm do FMR1 de um ponto antes do códon de início $A \cup G$, conhecida como tradução não AUG associada a repetições, ou tradução RAN (Repeat-Associated Non$A \cup G)$. Esse mecanismo já foi associado a outras doenças de expansão de trinucleotídeos, como a ataxia espinocerebelar tipo 8 , a distrofia miotônica 1 e a esclerose lateral amiotrófica/demência frontotemporal associada a C9orf72 (Cleary \& Ranum, 2013). Estudos indicam que a tradução RAN do gene $F M R 1$ leva à síntese de um produto atípico que não é produzido pela tradução iniciando em AUG, o peptídeo FRMpolyG, que contém uma sequência de poliglicina, como resultado da tradução ao longo da repetição CGG, e é tóxico para as células (Todd et al., 2013). FRMpolyG se encontra nos mesmos locais, em que há inclusões de FXTAS, tendo sido identificada no sistema nervoso central e em outros órgãos, em que se observam também as inclusões, como coração, tireoide e glândula adrenal (Buijsen et al., 2014).

O terceiro modelo proposto, diferentemente dos anteriores, envolve evento durante a transcrição através da região 5'UTR do gene FMR1, rica em CG, favorecendo a formação de alças $R$. Essas alças normalmente têm papel de proteção contra a metilação das ilhas CpG de promotores (Roy \& Lieber, 2009); entretanto, a formação excessiva dessas alças pode levar à ativação da resposta a dano de DNA, resultando em instabilidade genômica. Loomis et al. (2014) mostraram que, no caso do FMR1, a frequência e a complexidade estrutural das alças $R$ aumentam com o tamanho da repetição $(C G G)_{n}$ e com o nível de expressão do gene; concluíram que essa característica molecular do gene FMR1 está provavelmente associada com disfunções celulares.

Hagerman \& Hagerman (2016) consideram possível que esses três mecanismos estejam envolvidos na patogênese de FXTAS, porém elucidar qual o papel de cada um é importante para que possam ser 
desenvolvidas terapias, que teriam bases diferentes de acordo com cada um dos modelos.

Há também a possibilidade de que toxinas exógenas possam agravar ou até mesmo adiantar o início dos sintomas da FXTAS. Um estudo de 2005 descreveu uma mulher que, ao fazer tratamento quimioterápico para câncer de mama, apresentou piora no quadro de FXTAS (O'Dwyer et al., 2005). O principal fator externo que vem sendo associado à piora dos sinais de FXTAS é o consumo prolongado de álcool e opióides (Muzar et al., 2014b). O indivíduo mais jovem com FXTAS foi descrito por Martínez-Cerdeño et al. (2015): um homem de aproximadamente 30 anos de idade com longo histórico de uso de drogas e álcool, que possuía pré-mutação com repetição $(\mathrm{CGG})_{88}$; após sua morte por trauma, aos 36 anos, a análise do cérebro mostrou a presença das inclusões intranucleares típicas da FXTAS (Martínez-Cerdeño et al., 2015).

Existem trabalhos na literatura que relacionam o tamanho da repetição CGG com o grau e o tipo de comprometimento e também com a idade de início da FXTAS. Jacquemont et al. (2004b) descreveram forte correlação entre o risco de desenvolver FXTAS e o aumento da idade, e também mostraram que o risco é maior para os indivíduos do sexo masculino. Em um estudo subsequente, Jacquemont et al. (2006) relacionaram a ocorrência de FXTAS com o tamanho da repetição $(C G G)_{n}$. e sugeriram que indivíduos portadores de pré-mutação com repetição $(C G G)_{<70}$, quando apresentam FXTAS, as manifestações são leves ou atípicas. Tassone et al. (2007) relacionaram a idade de início de FXTAS com o tamanho da repetição.

\subsubsection{Insuficiência ovariana prematura associada ao X frágil (FXPOI)}

A insuficiência ovariana prematura (POF; Premature Ovarian Failure) é caracterizada pela cessação da menstruação antes dos 40 anos de idade, em decorrência de falência ovariana, e afeta cerca de $1 \%$ das mulheres da população geral. As causas da POF podem ser genéticas 
ou ambientais (Anasti, 1998), porém cerca de $60 \%$ dos casos de POF não têm causa definida (Murray et al., 1998).

Os primeiros relatos de maior incidência de POF entre as portadoras da pré-mutação do X frágil ocorreram ainda na década de 1990 (Cronister et al., 1991; Schwartz et al., 1994; Partington et al., 1996; Vianna-Morgante et al., 1996). Hoje sabe-se que FXPOI (Fragile $X$ associated Primary Ovary Insuficiency) afeta $21 \%$ das mulheres portadoras da pré-mutação (Allingham-Hawkins et al., 1999; ViannaMorgante et al., 1999; Sherman, 2000). Além disso, as portadoras de pré-mutação entram em menopausa aproximadamente 5 anos antes do que as mulheres da população geral (Murray et al., 2000). Outras manifestações clínicas da FXPOI podem incluir alterações nos ciclos menstruais, subfertilidade, aumento na taxa de gêmeos dizigóticos, aumento da frequência de aneuploidia na prole e de abortos espontâneos (te Velde \& Pearson, 2002).

O ganho de função do RNAm aparece também como mecanismo envolvido na FXPOI. Ausência ou diminuição dos níveis de proteína, decorrentes da mutação completa, não devem ser fatores de predisposição uma vez que portadoras de mutação completa não apresentam risco aumentado de terem menopausa precoce (Cronister et al., 1991 e Schwartz et al., 1994). O estudo realizado por Chang e et al. (2011) evidenciou a presença das inclusões intranucleares características de FXTAS nas células de ovários de mulheres com prémutação, levantando a hipótese de que o mecanismo molecular envolvido na FXPOI seja semelhante ao da FXTAS, e que as traduções RAN também ocorram nas mulheres com FXPOI (Buijsen et al., 2016).

O tamanho da repetição $(\mathrm{CGG})_{\mathrm{n}}$ no gene $F M R 1$ está associado com a idade do início da menopausa de forma não linear. A faixa entre as pré-mutações com repetições de 80 e 100 trincas de bases é a que confere maior risco para o desenvolvimento de FXPOI e para manifestação em idade mais precoce. Quando a repetição possui mais de 100 trincas CGG, o risco permanece maior do que o das mulheres da população geral, porém é menor do que aquele das portadoras de pré- 
mutação na faixa de tamanho da repetição entre 80 e 100 trincas de bases (Sullivan et al., 2005; Allen et al., 2007).

\subsection{Testes diagnósticos}

Estabelecida a associação do sítio frágil do cromossomo X (FRAXA) com a síndrome do $X$ frágil, o exame cromossômico, utilizando indutores do sítio frágil, passou a ser o teste diagnóstico indicado para a investigação da deficiência intelectual de causa desconhecida, especialmente em pessoas do sexo masculino (Jacky et al., 1991). Apesar do exame cromossômico se mostrar eficiente para o diagnóstico de meninos com SXF, as meninas com deficiência intelectual, nas famílias de afetados, frequentemente não manifestavam o sítio frágil; da mesma forma, indivíduos clinicamente normais, portadores certos, do gene alterado (depois identificados majoritariamente como portadores de pré-mutação) não expressavam o FRAXA.

Com a identificação do gene FMR1 em 1991 e o esclarecimento dos mecanismos que levam à SXF, foi possível o desenvolvimento de testes moleculares capazes de reconhecer tanto a mutação completa quanto a pré-mutação, em ambos os sexos. Logo o exame cromossômico foi substituído pela análise do gene $F M R 1$, como teste diagnóstico para a SXF. Durante muitos anos, o teste molecular adotado foi o Southern blotting, em que uma sonda correspondente a uma região do gene FMR1 é hibridada ao DNA genômico. Essa técnica permite reconhecer os alelos normais, os alelos pré-mutados e aqueles com mutação completa, mas não é capaz de identificar o número de trincas da repetição. A amplificação da repetição $(C G G)_{n}$ pela técnica de reação em cadeia de polimerase (PCR; Polimerase Chain Reaction) permite a definição do número de trincas de base; entretanto, até que a técnica fosse definida como padrão ouro para a análise do gene FMR1, foi preciso aprimorá-la, para que fosse possível realizar a amplificação de grandes segmentos ricos em CG, e o diagnóstico de mulheres heterozigóticas. Hoje já existem testes de PCR que permitem determinar 
tanto o tamanho da repetição quanto o status da metilação na região, com a identificação do espectro de alelos do FMR1 (Filipovic-Sadic et al., 2010; Chen et al., 2011). Atualmente, kits comerciais diagnósticos dos alelos do $F M R 1$ estão disponíveis.

Existe a possibilidade de realizar o teste pré-natal para a SXF, por meio da análise do gene FMR1 em DNA extraído de vilosidade coriônica ou de células do líquido amniótico, no início da gravidez (Monaghan et al., 2013; Biancalana et al., 2015). Já é possível também realizar o diagnóstico pré-implantacional da SXF. Para isso é necessário realizar a fertilização in vitro e a retirada de blastômeros para a análise do gene FMR1, com da implantação de embriões selecionados. Para assegurar o resultado, é realizada ainda a análise de lócus polimórficos ligados ao gene $F M R 1$ e a avaliação de marcadores para identificação do sexo do embrião (Chen et al., 2016).

\subsection{Aconselhamento Genético}

A SXF tem padrão de herança ligado ao $\mathrm{X}$ e é sempre herdada. $\mathrm{Na}$ maioria das vezes, a mãe do afetado possui uma pré-mutação que, ao ser transmitida, sofre expansão da repetição $(C G G)_{n}$, podendo manter-se ainda como pré-mutação ou ultrapassar as 200 trincas de bases e se tornar uma mutação completa (Fig. 2A). Quando o portador de prémutação é um homem, praticamente na totalidade dos casos, não ocorre expansão da repetição para mutação completa na transmissão para suas filhas que, assim, são todas portadoras de pré-mutação (Fig. 2C). Nas famílias com afetados pela SXF, o risco empírico para as portadoras de pré-mutação de terem filhos afetados é de $30 \%$, já esse risco para portadoras de mutação completa é de aproximadamente 40\% (Fig. 2B). 
A.

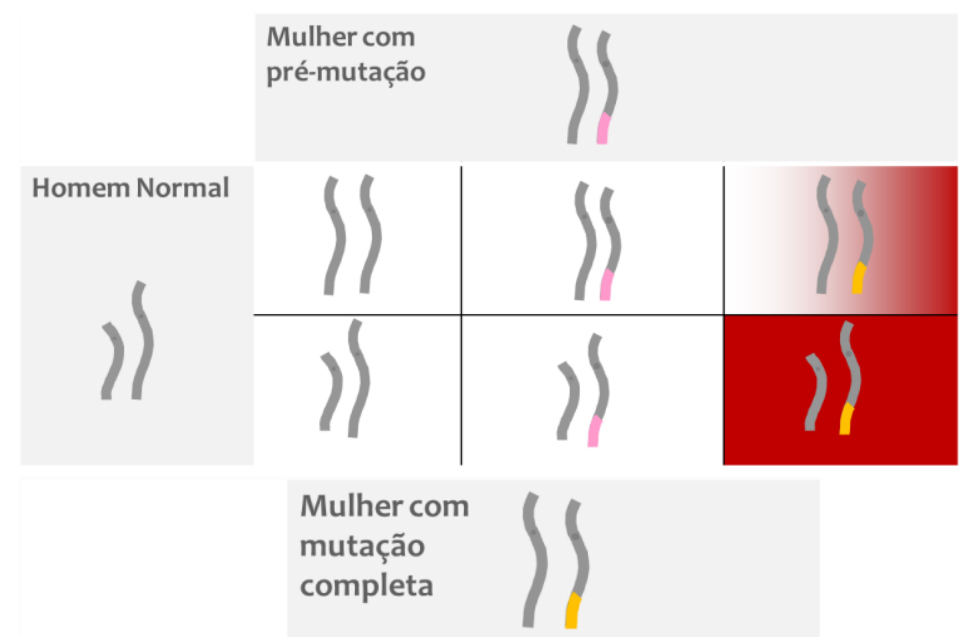

B.
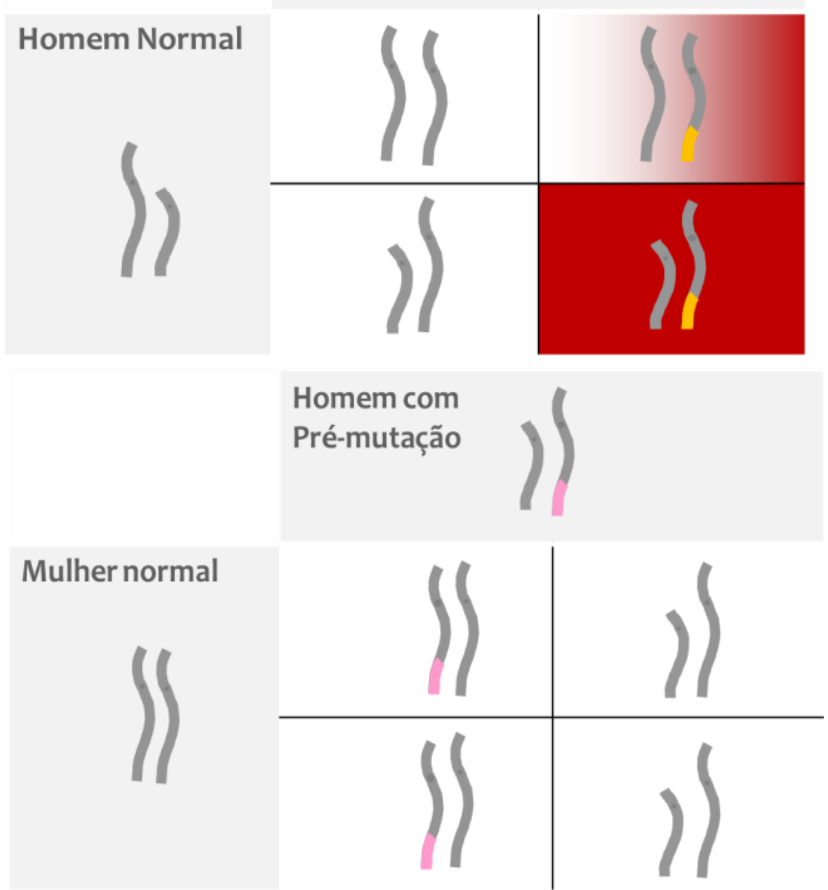

Figura 2: Herança do gene FMR1

A probabilidade de expansão de pré-mutação para mutação completa depende do tamanho da repetição (CGG) (Tabela 3). Nolin et al. (2003) analisaram a transmissão de alelos pré-mutados e intermediários por mulheres. Nesse estudo, foram investigadas amostras de 13 laboratórios de oito países. O menor alelo pré-mutado que expandiu para mutação completa em uma única geração, presente em duas mulheres, tinha $(\mathrm{CGG})_{59}$ e não possuía interrupção AGG. A comparação entre fetos masculinos e femininos não revelou diferença quanto à probabilidade de possuírem expansão para mutação completa. Adicionalmente, foi 
comparada a transmissão de alelos intermediários pelas mulheres, em famílias com e sem histórico de SXF, e, quando não havia SXF, os alelos foram mais estáveis ao serem transmitidos, a instabilidade aumentando com o tamanho da repetição.

Tabela 3: Risco de expansão da repetição $(C G G)_{n}$ para mutação completa, de acordo com o tamanho, na transmissão de pré-mutação por mulheres

\begin{tabular}{cc}
\hline $\begin{array}{c}\text { Tamanho da repetição (CGG) } \\
\text { materna }\end{array}$ & $\begin{array}{c}\text { Risco de expansão para a } \\
\text { mutação completa }\end{array}$ \\
\hline $55-59$ & $3,7 \%$ \\
$60-69$ & $5,3 \%$ \\
$70-79$ & $31,1 \%$ \\
$80-89$ & $57,8 \%$ \\
$90-99$ & $80,1 \%$ \\
$>100$ & $94-100 \%$ \\
\hline
\end{tabular}

Adaptado de Nolin et al., 2003

Apesar de a pré-mutação não se expandir para mutação completa na transmissão pelo homem portador, existem dois relatos na literatura de meninas portadoras de mosaicismo de pré-mutação e mutação completa, e pais portadores de pré-mutação. Zeesman et al. (2004) descreveram uma menina com atraso de desenvolvimento, portadora de pré-mutação e de mutação completa; seu pai apresentava o mesmo mosaicismo no sangue periférico, tendo a mutação completa parcialmente metilada; em espermatozoides, observou-se mosaicismo de tamanho de alelos pré-mutados. Alvarez-Mora et al. (2017) descreveram mosaicismo de alelos $(C G G)_{175} /(C G G)_{>200}$ em uma menina cujo pai era portador de alelo pré-mutado - $(\mathrm{CGG})_{88}$, em sangue periférico e (CGG) ${ }_{134}$, em espermatozódes; a peculiariedade desse alelo instável era sua repetição $(C G G)_{n}$ não possuir interrupções $A G G$, fator que contribui para a instabilidade da repetição (Nolin et al., 2014). Nos dois casos, a pré-mutação transmitida via espermatozoide deve ter-se expandido para mutação completa durante o desenvolvimento. Esses relatos de situação rara alertam para a possibilidade de alelos prémutados altamente instáveis, que podem expandir-se para mutação completa, quando herdados via paterna. 
O diagnóstico de crianças afetadas pela SXF é importante para alertar os pais sobre a possibilidade de recorrência e também para a identificação de familiares, particularmente mulheres, que possam ser portadoras de pré-mutação ou de mutação completa, para oferecer-lhes testes e aconselhamento genético.

Com o avanço dos estudos das doenças de manifestação tardia associadas ao gene FMR1, é importante ressaltar que identificar uma pré-mutação em indivíduos clinicamente normais é preditivo para FXTAS, e também para FXPOI em mulheres. As implicações desses diagnósticos devem ser bem esclarecidas durante 0 aconselhamento genético pré-teste.

Por se tratarem de doenças genéticas com herança e mecanismo genético complexos, e o teste para SXF ser um dos testes genéticos mais frequentemente realizados, organizações envolvidas com a prática genética formularam documentos com os padrões e diretrizes para 0 teste do gene FMR1, tanto para a SXF quanto para as outras doenças associadas ao gene FMR1. O primeiro, publicado em 2001, pelo American College of Medical Genetics and Genomics (ACMG), marcou o início de uma série a tratar de doenças específicas (Maddalena et al., 2001); o documento teve sua última atualização publicada em 2013 (Monaghan et al., 2013). Há também uma publicação da European Molecular Genetics Quality Network (EMQN) (Biancalana et al., 2015). Tanto as publicações da ACMG quanto da EMQN trazem considerações a respeito dos diferentes testes genéticos disponíveis para a análise do gene FMR1 e quais informações devem constar nos laudos emitidos aos pacientes, e são direcionados a profissionais da área da genética e laboratórios.

A National Society of Genetic Counselors (NSGC) também publicou suas orientações a respeito das doenças associadas ao gene FMR1 (Finucane et al., 2012), no entanto, com foco maior no aconselhamento genético, pré-teste e pós-teste, e voltado para profissionais que realizam o aconselhamento genético. Dentre as orientações do pré-teste é levantado o fato de que poucos profissionais da área estão familiarizados com FXTAS e FXPOI e muitos subestimam sua pesquisa 
em famílias que podem estar em risco para a SXF; um ponto essencial salientado é a construção de heredograma da família, com atenção para a diversidade de sinais clínicos que podem estar relacionados ao FMR1. O papel dos aconselhadores genéticos é fundamental para fornecer informações pré-teste e preparar os indivíduos para os possíveis resultados. As orientações relativas às doenças associadas ao gene FMR1 estão sumarizadas a seguir.

a) Considerações gerais:

- avaliar o conhecimento dos indivíduos sobre as doenças associadas ao gene FMR1;

- discutir as implicações da detecção de alelos prémutados, intermediários e com mutação completa;

- levantar as opções de acompanhamento pós-teste;

- discutir as reações emocionais e efeitos dos possíveis resultados.

b) Para os pacientes encaminhados com história conhecida na família de doenças associadas ao gene FMR1:

- colher as experiências dos pacientes com os familiares, incluindo posturas em relação à deficiência;

- avaliar a autopercepção do risco genético;

- utilizar o histórico familial para exemplificar os padrões de herança;

- se adequado, incluir na discussão do aconselhamento genético as crianças em risco;

- levantar benefícios e malefícios de se testarem crianças e adolescentes pré-sintomáticos em risco.

c) Para adultos encaminhados com comprometimento cognitivo e/ou comportamental:

- identificar os sinais neurológicos da SXF ou da FXTAS que podem afetar a compreensão e a decisão do paciente;

- verificar o estado de tutela do paciente antes do teste, se apropriado; 
- incluir membros da família ou cuidadores na discussão, com a permissão do paciente;

- acessar recursos de trabalho jurídico e social para questões relativas a competência e consentimento informado para testes genéticos.

d) Para testes pré-natais:

- alertar a paciente que um posterior teste de amniocentese pode ser necessário para esclarecer 0 resultado do teste em vilosidade coriônica.

Deve-se ressaltar, para os indivíduos com resultado negativo do teste para mutações no gene $F M R 1$, que outras alterações genéticas não ficam excluídas. 


\section{OBJETIVOS}

O objetivo principal deste trabalho foi investigar duas famílias cujos casos índice foram encaminhados para o Centro de Pesquisa sobre o Genoma Humano e Células-Tronco (CEGH-CEL), do Instituto de Biociências da USP, para pesquisa de ataxia espinocerebelar e nas quais a avaliação clínica e a história familial indicaram a possibilidade diagnóstica de FXTAS. A identificação de pré-mutação do gene FMR1 nessas pessoas permitiu confirmar o diagnóstico.

Os objetivos específicos incluíram oferecer avaliação clínica, teste do gene FMR1 e aconselhamento genético aos indivíduos das famílias que assim o desejaram, permitindo esclarecer a causa de condições como falência ovariana prematura, deficiência intelectual e dificuldade de aprendizado. 


\section{CASUÍSTICA E MÉTODOS}

\subsection{Casuística}

Foram estudadas duas famílias averiguadas por dois indivíduos encaminhados ao CEGH-CEL para realizar testes moleculares, pois apresentavam hipótese diagnóstica de ataxia espinocerebelar. Após avaliação clínica, história familial detalhada com construção dos heredogramas e revisão de exames de imagem, a hipótese diagnóstica levantada para os casos índice foi de FXTAS.

\subsection{Aspectos éticos}

O projeto de pesquisa teve a aprovação do Comitê de Ética em Pesquisa (CEP) do Instituto de Biociências (IB-USP) (CAAE: 69239117.1.0000.5464).

Os pacientes ou seus responsáveis foram informados dos objetivos do projeto e assinaram Termo de Consentimento Livre e Esclarecido.

\subsection{Avaliação clínica}

A avaliação clínica dos pacientes foi realizada pela equipe do Ambulatório de Neurogenética da Faculdade de Medicina da Universidade de São Paulo (FMUSP). Para a avaliação do desempenho cognitivo, foi utilizado o Montreal Cognitive Assessment - MoCA (Apêndice A) 


\subsection{Testes genéticos laboratoriais}

Os testes moleculares para $\mathrm{X}$ frágil e a análise cromossômica foram realizados no Laboratório de Genética Humana do Departamento de Genética e Biologia Evolutiva, IB-USP.

\subsubsection{Teste molecular para a síndrome do $\mathrm{X}$ frágil}

A extração do DNA de linfócitos do sangue periférico foi realizada automaticamente, utilizando o aparelho Autopure LS (Gentra Systems, Minneapolis, USA).

$\mathrm{O}$ número de trincas de bases da repetição $(C G G)_{n}$ do gene $F M R 1$ foi determinado por PCR, usando os reagentes AmplideX® FMR1 PCR ou AmplideX® FMR1 mPCR (Asuragen), e eletroforese capilar (analisador genético ABI 3700; Applied Biosystems, USA).

\subsubsection{Análise cromossômica}

Para o estudo cromossômico, as preparações foram obtidas a partir de cultura temporária de linfócitos de sangue periférico. A análise foi realizada após bandamento $\mathrm{G}$. 


\section{RESULTADOS E DISCUSSÃO}

\subsection{Família 1 (Fig. 3)}

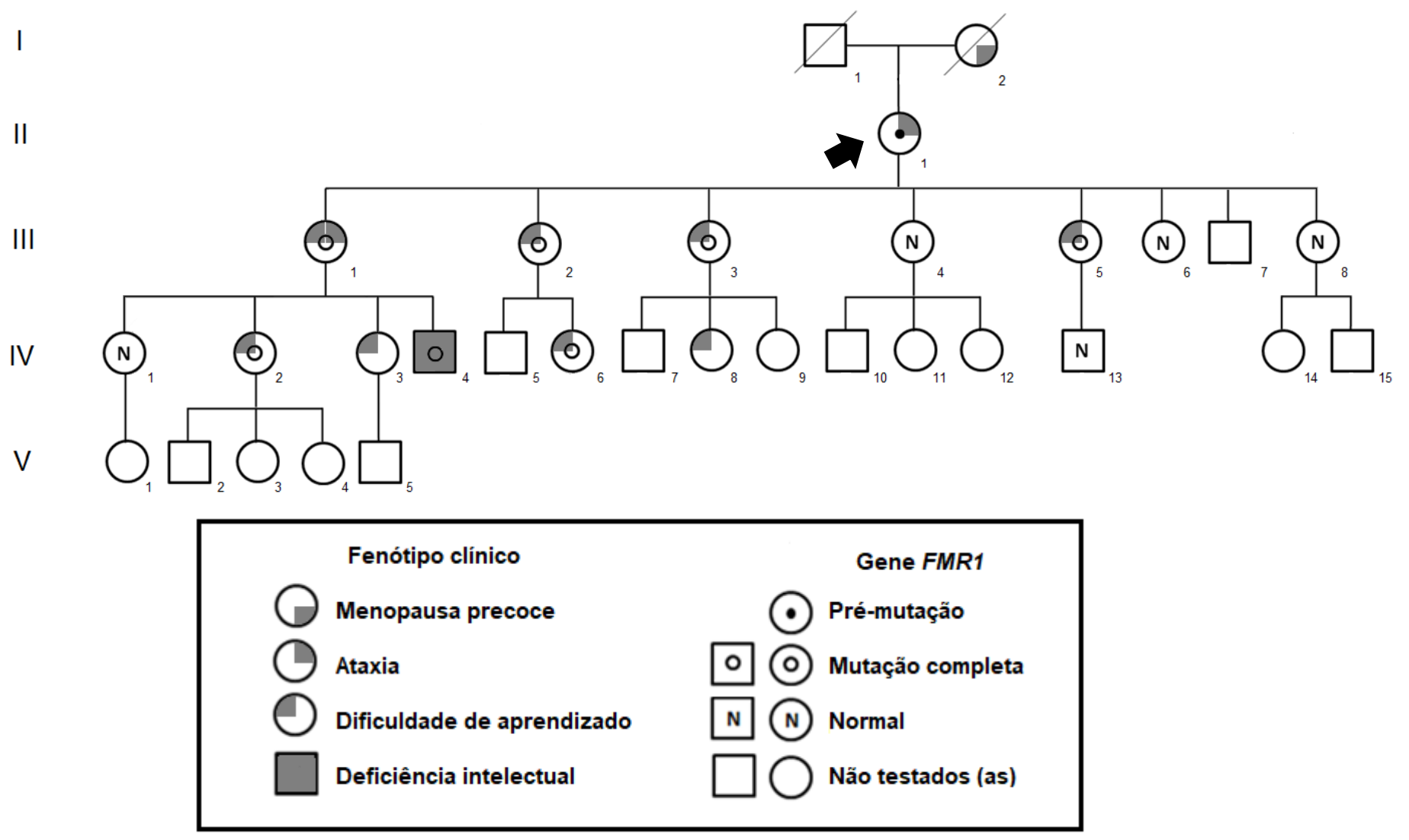

Figura 3: Heredograma da Família 1

\subsubsection{Propósita (Fig. 3; II-1)}

A propósita, uma mulher de 81 anos, em consulta no CEGH-CEL, relatou dificuldade para caminhar, de caráter progressivo, iniciando cerca de 10 anos antes; andava naquele momento somente com apoio, quadro este associado a disartria. Negou dificuldade para segurar objetos ou tremores.

Ao exame neurológico observou-se claro declínio cognitivo: a fluência verbal estava reduzida, não conseguiu nomear objetos nem fazer contas. Caminhou com marcha de pequenos passos, desequilibrando-se com facilidade. 
Filha única com ensino superior completo, seu pai faleceu aos 30 anos de idade, sem causa conhecida. Sua mãe apresentou menopausa precoce, com aproximadamente 35 anos; foi relatado que, em idade avançada, apresentou dificuldades motoras e declínio cognitivo, tendo recebido diagnóstico de doença de Alzheimer; faleceu com cerca de 90 anos. A propósita teve oito filhos (sete do sexo feminino e um, do masculino) e quatro de suas filhas tiveram dificuldade de aprendizado (III-1, 2, 3 e 5); para uma delas (III-1) foi relatado ter quadro similar ao da mãe, com início aos 50 anos, andando com dificuldade. Foi também relatada deficiência intelectual em neto (IV-4).

A ressonância magnética de crânio revelou atrofia significativa de cerebelo e leucopatia, afetando a região frontal.

Levando em consideração o quadro clínico, a imagem de ressonância magnética de crânio e a história familial de menopausa precoce, dificuldade de aprendizado e deficiência intelectual, foi levantada para a propósita a hipótese diagnóstica de FXTAS.

A análise do gene FMR1 mostrou que a propósita é heterozigótica quanto a uma pré-mutação do gene $F M R 1$, tendo o alelo pré-mutado

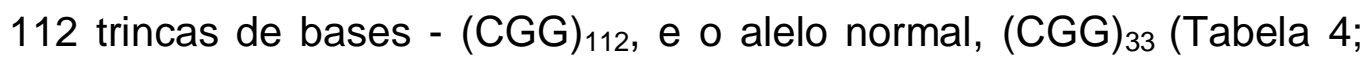
pág. 44). Foi feita nova avaliação clínica e realizado teste neurocognitivo, considerando os critérios diagnósticos de FXTAS. (Tabela 2; pág. 24)

A reavaliação neurológica, realizada um ano após a primeira consulta mostrou:

a) Ataxia de predomínio axial e apendicular de membros inferiores;

b) Declínio cognitivo de moderado a grave, desatenção e perseveração (comprometimento do Digit Span direto e inverso, Luria, Ozeretzki e teste do aplauso comprometidos). O desempenho no teste de triagem Montreal Cognitive Assessment (MoCA) foi de 6/30;

c) Tremor de repouso e de ação, simétrico e bilateral;

d) Sinais de frontalização caracterizado por presença de grasping e groping e reflexos axiais da face exaltados; 
e) Disartria, com fluência verbal fonêmica e semântica diminuídas e compressão preservada;

f) Apraxia para imitação de gestos, da mímica de uso de objetos únicos e multitarefas;

g) Força muscular conservada, grau IV, bilateralmente;

h) Bradicinesia, com paratonia inibitória;

i) Marcha realizada apenas com apoio, com passos curtos;

j) Nistagmo optocinético alterado.

A ressonância magnética de encéfalo realizada em julho de 2014 revelou atrofia cerebral e de cerebelo e leucoencefalopatia frontal (Figura 4).

Portanto, segundo os critérios diagnósticos para FXTAS, a propósita preenchia critérios de provável FXTAS, pois apresentava dois sinais clínicos principais, o tremor intencional e a ataxia cerebelar, além de sinais radiológicos secundários - lesões na substância branca cerebral e atrofia cerebral generalizada. 


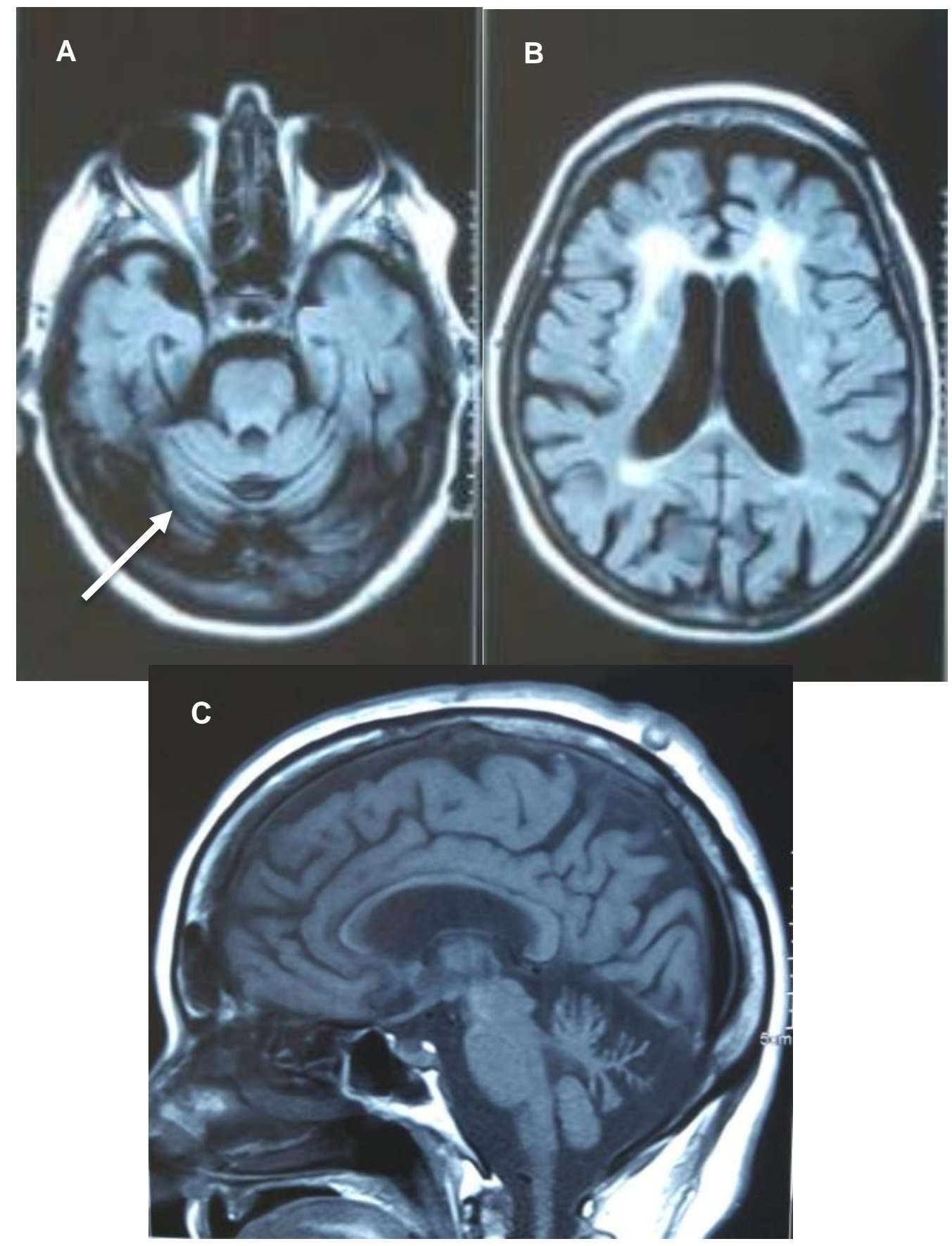

Figura 4: Imagem de ressoância magnética de crânio da propósita (II-1): A. Sequência axial FLAIR. Atrofia cerebelar (seta); B. Sequência axial FLAIR. Leucoencefalopatia de predomínio frontal; C. Sequência sagital ponderada em T1. Acentuada atrofia cerebelar. 


\subsubsection{Primogênita da propósita (III-1)}

Foi realizada avaliação clínica e teste neurocognitivo na primogênita da propósita (Fig. 3; III-1), pois foi relatado que ela apresentava quadro semelhante ao de sua mãe.

Com 59 anos de idade e ensino médio completo, sempre apresentou dificuldades no relacionamento interpessoal e para tomar decisões que envolvessem finanças, autocuidado e gestão da família e do domicílio. Seu relacionamento com a família e com o esposo era turbulento e marcado algumas vezes por violência.

Nos últimos quatro anos, algumas dessas características tornaram-se mais evidentes e, adicionalmente, a paciente passou a ter dificuldade para falar, com discurso empobrecido e lacônico. Mostrava-se apática e seu maior interesse era assistir televisão. Deixou de ter autonomia para as atividades da vida diária.

A avaliação neurológica mostrou:

a) Desempenho cognitivo no teste de triagem Montreal Cognitive Assessment (MoCA) foi de 14/30;

b) Fluência verbal fonêmica e semântica comprometida;

c) Apraxia para imitação de gestos, da mímica de uso de objetos únicos e multitarefas;

d) Força muscular conservada, grau IV, bilateralmente;

e) Disartria e ataxia cerebelar discreta, de predomínio axial, com dismetria de MMSS e MMII. Não apresentava tremor.

Não foi possível realizar estudos de imagem em decorrência de sua baixa adesão a recomendações médicas.

Assim, foi possível caracterizar que ela apresentava disfunção executiva com impacto na sua capacidade de tomar decisões, e seu desempenho se agravou nos últimos anos, com comprometimento da comunicação (disartria), praxias e coordenação (ataxia leve), não acompanhada de tremores.

Apesar da variabilidade de sinais clínicos da FXTAS, a maioria dos pacientes apresenta a ataxia ou o tremor intencional como principal 
sintoma; no entanto, estudos mostraram casos em que o principal sinal era o comprometimento cognitivo. Mothersead e col. (2005) relataram um caso atípico, um homem com pré-mutação - (CGG) ${ }_{93}$ apresentando demência de progressão rápida, tremores, ataxia e alterações de substância branca. Outro estudo descreveu um paciente com (CGG) 85 em que o principal sinal clínico era o declínio cognitivo com rápida progressão, enquanto as alterações motoras eram menos graves e permaneceram inalteradas; a neuroimagem foi característica de FXTAS (Gonçalves et al., 2007). Fatores que pudessem estar contribuindo para o predomínio de declínio cognitivo nesses casos não ficaram claros.

A análise do gene FMR1 de III-1 identificou um alelo com mutação completa - $(C G G)_{>200}$ e outro normal, com $(C G G)_{29}$. Uma vez que já foram relatados na literatura indivíduos com FXTAS que apresentavam a mutação completa desmetilada (Loesch et al., 2012), foi realizada a análise da metilação da repetição $(\mathrm{CGG})_{n}$, verificando-se que o alelo mutado estava completamente metilado, como ocorre na quase totalidade dos casos. Dessa forma, a hipótese diagnóstica de FXTAS não se sustentou, uma vez que ela não apresentava pré-mutação ou alelo desmetilado em FMR1. Desta forma, a etiologia da síndrome demencial de III-1 não foi esclarecida. Existem, no entanto, poucos estudos a respeito do envelhecimento em mulheres com mutação completa do gene FMR1.

\subsubsection{Neto da propósita (IV-4)}

Homem com 30 anos, filho de III-1, possui deficiência intelectual grave e características comportamentais típicas de SXF, tais como falta de sustento do olhar, hiperatividade e estereotipias motoras. Frequentou a APAE durante muitos anos; não aprendeu a ler nem a escrever. Nele foi identificada mutação completa - $(\mathrm{CGG})_{>200}$, estabelecendo-se 0 diagnóstico de SXF. 


\subsubsection{Demais indivíduos da família}

O teste para $X$ frágil mostrou que III-4, III-6, III-8 e IV-13 não têm alteração no gene FMR1 (Fig. 3). Nas mulheres III-2, III-3, III-5, IV-2 e IV-6, foram detectadas mutações completas, o que explica a presença de dificuldade de aprendizado.

Os resultados da análise do gene FMR1 na Família 1 estão apresentados na Tabela 4.

Tabela 4: Análise da repetição $(\mathrm{CGG})_{\mathrm{n}}$ do gene $F M R 1$ na Família 1

\begin{tabular}{ccccc}
\hline $\begin{array}{c}\text { Indivíduo } \\
\text { (Heredograma } \\
\text { Fig. 3) }\end{array}$ & $\begin{array}{c}\text { Idade } \\
\text { (em anos) }\end{array}$ & Sexo & (CGG) & RESULTADo \\
\hline II.1 & 81 & Feminino & $33 / 112$ & Pré-mutação \\
III.1 & 59 & Feminino & $29 />200$ & Mutação completa \\
III.2 & 57 & Feminino & $29 />200$ & Mutação completa \\
III.3 & 55 & Feminino & $29 />200$ & Mutação completa \\
III.4 & 52 & Feminino & $29 / 33$ & Normal \\
III.5 & 51 & Feminino & $29 />200$ & Mutação completa \\
III.6 & 49 & Feminino & $29 / 33$ & Normal \\
III.8 & 43 & Feminino & $29 / 33$ & Normal \\
IV.1 & 34 & Feminino & $29 / 45$ & Normal \\
IV.2 & 33 & Feminino & $45 />200$ & Mutação completa \\
IV.4 & 30 & Masculino & $>200$ & Mutação completa \\
IV.6 & 32 & Feminino & $29 />200$ & Mutação completa \\
IV.13 & 31 & Masculino & 29 & Normal \\
\hline
\end{tabular}

\subsubsection{Aconselhamento genético para a Família 1}

$O$ aconselhamento genético foi feito para esclarecer as informações a respeito de todas as doenças associadas ao gene FMR1. A família foi orientada a conversar com os outros parentes que não participaram da pesquisa, principalmente aqueles para quem foi relatada dificuldade de aprendizado, a respeito da síndrome do $\mathrm{X}$ frágil e sobre a importância da análise molecular do gene FMR1.

A neta IV-2 foi orientada a informar seus filhos a respeito da mutação do gene presente na família e do teste do gene FMR1 para identificar portadores, quando tivessem maturidade para entender as implicações 
do resultado. Além disso, as netas IV-2 e IV-6 foram informadas quanto ao risco de futuros filhos com SXF.

Relatórios sobre os resultados dos exames e o aconselhamento genético foram entregues aos participantes ou seus responsáveis.

\subsection{Família 2 (Fig. 5)}

I

II

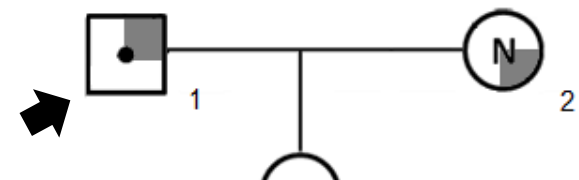

III
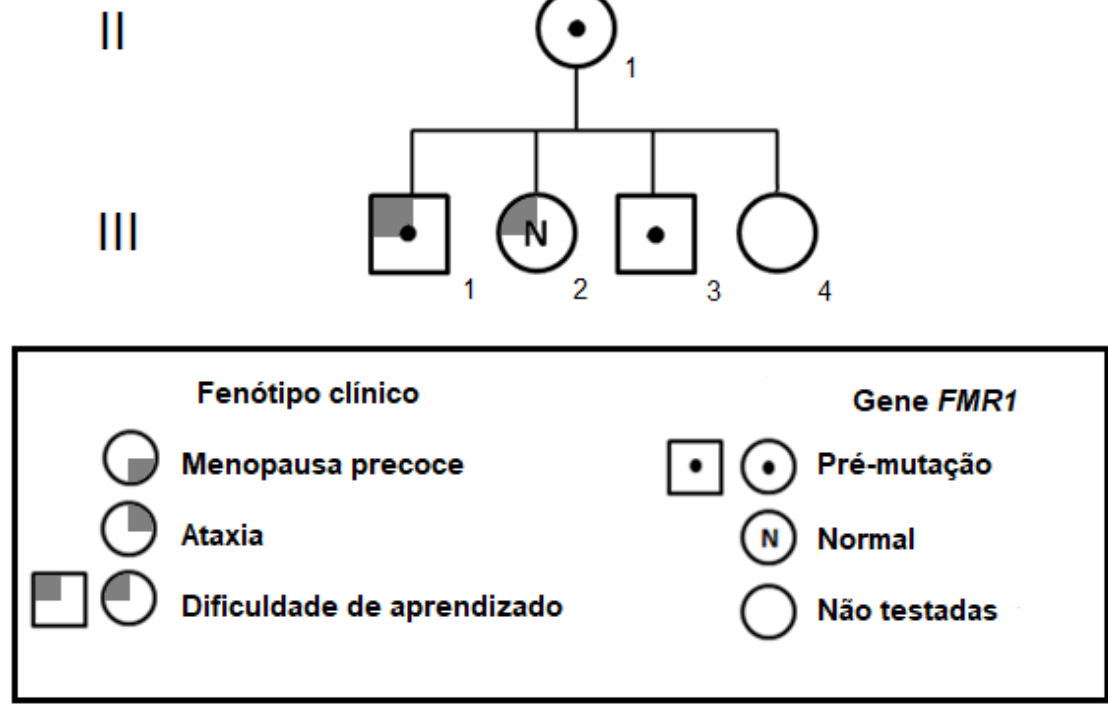

Figura 5: Heredograma da Família 2.

\subsubsection{Propósito (Fig. 5; I-1)}

O propósito, um homem de 58 anos, em consulta no CEGH-CEL, relatou que começou a apresentar desequilíbrio havia nove anos, derrubando objetos e caindo com facilidade. Era capaz de andar apenas com apoio, tendo piora na articulação da fala; a família não o considerava como tendo declínio cognitivo, uma vez que ele mantinha a capacidade de ler e de fazer contas. Com quatro anos de escolaridade, trabalhou em atividade agrícola, estando aposentado havia seis anos por 
invalidez. Tinha historia de consumo abusivo de álcool por muitos anos. A ressonância magnética de crânio mostrou atrofia cerebelar leve.

Sua mãe faleceu aos 72 anos de idade e seu pai, antes do seu nascimento; não manteve contato com a família paterna, o que impossibilitou a obtenção de mais informações sobre a história familial. Possui uma única filha e três netos, dois dos quais relatados como tendo dificuldade de aprendizado.

Ao exame neurológico, observou-se:

a) Declínio cognitivo com fluência verbal diminuída;

b) Dispraxia da marcha, ideativa e ideamotora, com dificuldade em realizar movimentos alternados;

c) Ataxia leve, com alargamento da base de sustentação;

d) Marcha realizada com passos pequenos, sem movimentos associados e leve tremor de atitude e de repouso.

A análise do gene FMR1 mostrou a presença de pré-mutação $(C G G)_{62}$, no propósito (Tabela 5; pág. 48). Foi feita nova avaliação física e também realizado teste neurocognitivo, considerando os critérios diagnósticos de FXTAS. (Tabela 2; pág. 24).

A reavaliação neurológica, realizada dois anos após a primeira consulta, mostrou claro agravamento de seu desempenho mostrando:

a) Síndrome cerebelar, com ataxia axial e apendicular com seguimento sacádico e sacadicas hipométricas;

b) Tremor intencional, cefálico e titubeio;

c) Síndrome demencial grave, com MoCA de 5/30, acompanhado de sinais de frontalização (Grasping e groping presentes e reflexos axiais da face vivos);

d) Síndrome parkinsoniana, com sinal da roda denteada, bradicinesia e rigidez; paralisia do supranuclear;

e) Disfagia e disartria.

Portanto, seguindo os critérios diagnósticos, o propósito recebeu diagnóstico provável de FXTAS, pois apresentava dois sinais clínicos principais: tremor intencional e ataxia cerebelar. 
Chama a atenção a idade relativamente precoce da manifestação de sinais clínicos, especialmente considerando-se o tamanho da repetição da pré-mutação presente no propósito, uma vez que na literatura, os sintomas de FXTAS foram observados em $17 \%$ dos homens com prémutação aos 50-59 anos, em 38\%, aos 60-69 anos, em 47\%, aos $70-79$ e em $75 \%$ aos $\geq 80$ anos (Jacquemont et al., 2004b); além disso, os alelos maiores do que aproximadamente 70 repetições são mais prováveis de levar à FXTAS (Jacquemont et al., 2006). Alguns casos semelhantes, entretanto, já foram descritos (Hagerman \& Hagerman, 2007a). Um dos fatores que pode ter influenciado o início de FXTAS foi o consumo prolongado de bebida alcoólica, relatado pela filha do propósito, e que já foi associado a rápida deterioração neurológica em FXTAS (Muzar et al., 2014b).

\subsubsection{Primogênita do propósito (II-1)}

Mulher, 31 anos, assintomática e portadora obrigatória de prémutação, o que foi confirmado pelo teste do gene $F M R 1$, que identificou um alelo normal $(\mathrm{CGG})_{26}$ e um pré-mutado $(\mathrm{CGG})_{62}$.

\subsubsection{Netos do propósito (III-1 e III-3)}

Foi relatado que o neto mais velho (III-1), então com 16 anos, possuía dificuldade de aprendizado; nele foi identificada uma prémutação - (CGG) ${ }_{65}$, o que não explica essa dificuldade de aprendizado.

No outro neto (III-3), com 5 anos de idade, foram identificados dois alelos com $(C G G)_{49}$ e $(C G G)_{64}$. Como sua mãe possui alelos com $(C G G)_{29}$ e (CGG) $)_{62}$, o alelo com (CGG) ${ }_{49}$ deve ter resultado de contração do alelo pré-mutado. $O$ exame cromossômico revelou cariótipo normal $(46, X Y)$, excluindo a possibilidade de síndrome de Klinefelter e indicou, portanto, tratar-se de mosaicismo de pré-mutação e alelo intermediário (gray-zone), com origem pós-zigótica. Contrações da repetição (CGG) de pré-mutações e mutações completas do gene FMR1 ocorrem devido 
a sua instabilidade, relacionada à ausência de interrupções $A G G$ na repetição $(C G G)_{n}$ ou à presença dessas interrupções em pequeno número (Mingroni-Netto et al., 1996; Finucane et al., 2012). Entretanto, não encontramos relato da presença de alelo intermediário associado a pré-mutação, em um mesmo indivíduo.

\subsubsection{Demais indivíduos}

Foi realizado o teste molecular para $X$ frágil na esposa (I-2) do propósito, pois foi relatada menopausa precoce. No entanto, o teste identificou dois alelos normais - $(\mathrm{CGG})_{26}$ e $(C G G)_{28}$, sendo descartada a possibilidade de FXPOI.

A realização do teste molecular para $X$ frágil não identificou alterações na neta (III-2) do propósito. Portanto, a dificuldade de aprendizado, relatada por sua mãe, não se deve a mutação do gene FMR1.

Os resultados da análise do gene FMR1 na Família 2 estão apresentados na Tabela 5.

Tabela 5: Análise da repetição $(\mathrm{CGG})_{\mathrm{n}}$ do gene $F M R 1$ na Família 2

\begin{tabular}{|c|c|c|c|c|}
\hline $\begin{array}{l}\text { Indivíduo } \\
\text { 'Heredograma } \\
\text { Fig. 5) }\end{array}$ & $\begin{array}{c}\text { Idade } \\
\text { (em anos) }\end{array}$ & Sexo & $(C G G)_{n}$ & RESULTADO \\
\hline I-1 & 58 & Masculino & 62 & Pré-mutação \\
\hline I-2 & 54 & Feminino & $26 / 28$ & Normal \\
\hline |l-1 & 32 & Feminino & $26 / 62$ & Pré-mutação \\
\hline III-1 & 16 & Masculino & 65 & Pré-mutação \\
\hline III-2 & 11 & Feminino & $26 / 30$ & $\begin{array}{c}\text { Normal } \\
\text { Mosaicismo }\end{array}$ \\
\hline III-3 & 5 & Masculino & $49 / 64$ & $\begin{array}{l}\text { intermediário/ pré- } \\
\text { mutacão }\end{array}$ \\
\hline
\end{tabular}

\subsubsection{Aconselhamento genético para a Família 2}

A síndrome do $X$ frágil (SXF) é bem conhecida como a causa mais frequente de deficiência intelectual herdada; já a FXTAS e as outras doenças associadas à pré-mutação do gene $F M R 1$ são bem menos 
consideradas como hipótese diagnóstica. $\mathrm{O}$ diagnóstico de FXTAS e dessas outras doenças é mais frequentemente feito a partir da identificação de indivíduos que apresentam a síndrome do $X$ frágil, raramente os afetados sendo os casos-índice. Entretanto, o diagnóstico das síndromes associadas à pré-mutação do gene $F M R 1$, em famílias em que não ocorreu a síndrome do $X$ frágil, como a família em questão, é importante para o aconselhamento genético quanto à ocorrência de deficiência intelectual.

A análise molecular do gene FMR1 no propósito foi um teste preditivo para sua filha (II-1) em relação às doenças associadas à pré-mutação do gene FMR1, pois ela obrigatoriamente herdou um alelo com a prémutação. Portanto, foram dadas informações quanto à FXTAS e também foi realizado 0 aconselhamento reprodutivo, informando o risco de FXPOI e o risco de mutação completa em sua futura prole e a ocorrência da SXF.

Os menores III-1 e III-2 foram testados por conta da dificuldade de aprendizado relatada pela mãe, já o indivíduo III-4 foi testado a pedido da mãe. $O$ teste para $X$ frágil em crianças assintomáticas traz riscos $\mathrm{e}$ benefícios. Ao se testar uma menina, é preciso esclarecer aos responsáveis as implicações do teste: quando o resultado é de prémutação, é preciso orientar quanto ao risco de expansão na futura prole, à ocorrência de SXF e quanto às doenças de manifestação tardia associadas à pré-mutação do gene FMR1; quando o resultado é de mutação completa, além do risco de SXF em crianças que venha a ter, é preciso orientação para evitar estigmatizar a criança e associar qualquer comportamento inadequado com a mutação; assim, deve-se considerar limitar a divulgação da informação de que a menina possui a mutação completa. Quando o teste é realizado em meninos assintomáticos há a possibilidade de o resultado ser de alelo pré-mutado ou alelo normal, não sendo um teste necessário para o aconselhamento reprodutivo, uma vez que não há risco significativo de futura prole com SXF. Por outro lado, a identificação de pré-mutação é preditiva para FXTAS, com risco alto, não tendo sido dada a oportunidade de essa pessoa decidir sobre submeter-se ou não ao teste. Assim, com relação a criança clinicamente 
normal, consideramos o adequado transmitir a seus responsáveis, inclusive por escrito, a informação sobre a probabilidade de ela ser portadora do gene FMR1 alterado, os riscos reprodutivos e as doenças de manifestação tardia associadas ao gene FMR1, mostrando a importância de comunicar-lhe o resultado do teste alterado quando ela atingir maturidade para entendê-lo, com a indicação de então consultar geneticista.

Relatórios sobre os resultados dos exames e o aconselhamento genético foram entregues aos participantes ou seus responsáveis. 


\section{CONCLUSÕES}

1. Tendo em vista a sua variada apresentação fenotípica, a possibilidade de uma condição associada ao gene FMR1 deve ser considerada frente a diversos fenótipos: deficiência intelectual, dificuldade de aprendizado, falência ovariana prematura e síndrome de tremor-ataxia associada ao $\mathrm{X}$ frágil.

2. Nas duas famílias aqui investigadas, a obtenção de história familial detalhada permitiu identificar outras pessoas com problemas aparentemente não relacionados, mas que poderiam fazer parte do espectro fenotípico associado ao gene FMR1.

3. A investigação do "topo para a base", no qual o caso-índice é um indivíduo com FXTAS, não é frequente, uma vez que, na maioria das famílias, o diagnóstico de uma condição associada ao FMR1 é estabelecido a partir da investigação de um indivíduo do sexo masculino com deficiência intelectual devida à síndrome do X-frágil. Isso provavelmente decorre do menor conhecimento sobre FXTAS.

4. O conhecimento das diversas faces das condições associadas ao gene FMR1 é necessário tanto para o diagnóstico, como para o adequado aconselhamento genético das famílias. 


\section{REFERÊNCIAS BIBLIOGRÁFICAS}

Adams JS, Adams PE, Nguyen D, et al. Volumetric brain changes in females with fragile $X$-associated tremor/ataxia syndrome (FXTAS). Neurology 2007;69:851-859.

Allen et al. Examination of reproductive aging milestones among women who carry the FMR1 premutation. Hum. Reprod. 2007;22: 2142-2152.

Allingham-Hawkins DJ, et al. Fragile $X$ premutation is a significant risk factor for premature ovarian failure: the International Collaborative POF in Fragile X study - preliminary data. Am J Med Genet. 1999;83(4):3225.

Alvarez-Mora MI, Guitart M, Rodriguez-Revenga L, Madrigal I, Gabau E, Milà M. Paternal transmission of a FMR1 full mutation allele. Am J Med Genet Part A. 2017;173A:2795-2797

Anasti JN. Premature ovarian failure: an update. Fertil Steril. 1998;70(1):1-15.

Apartis E, Blancher A, et al. FXTAS: new insights and the need for revised diagnostic criteria. Neurology. 2012;79(18):1898-907.

Ashley CT Jr, Wilkinson KD, Reines D, Warren ST. FMR1 protein: conserved RNP family domains and selective RNA binding. Science. 1993;262(5133):563-6.

Ashley-Koch, A.E., Robinson, H., Glicksman, A. E., Nolin, S. L., Schwartz, C. E., Brown, W. T., Turner, G. and Sherman, S. L. Examination of factors associated with instability of the FMR1 CGG repeat. Am J Hum Genet. 1998;63, 776-785.

Au J, Akins RS, Berkowitz-Sutherland L, et al. Prevalence and Risk of Migraine Headaches in Adult Fragile X Premutation Carriers. Clinical genetics. 2013;84(6):546-551.

Biancalana V, Glaeser D, McQuaid S, Steinbach P. EMQN best practice guidelines for the molecular genetic testing and reporting of fragile $X$ syndrome and other fragile X-associated disorders. Eur J Hum Genet. 2015;23(4):417-25.

Bourgeois JA, Seritan AL, Casillas EM, HessI D, Schneider A, Yang Y, Kaur I, Cogswell JB, Nguyen DV, Hagerman RJ. Lifetime prevalence of mood and anxiety disorders in fragile $X$ premutation carriers. J Clin Psychiatry. $2011 ; 72(2): 175-82$.

Bowen P, Biederman B, Swallow KA. The X-linked syndrome of macroorchidism and mental retardation: further observations. Am J Med Genet. 1978;2(4):409-14. 
Brackett DM, Qing F, Amieux PS, Sellers DL, Horner PJ, Morris DR. FMR1 transcript isoforms: association with polyribosomes; regional and developmental expression in mouse brain. PLoS One. 2013;8(3):e58296.

Brunberg JA, Jacquemont S, Hagerman RJ, et al. Fragile $\mathrm{X}$ premutation car-21. riers: characteristic MR imaging findings of adult male patients with pro -gressive cerebellar and cognitive dysfunction. Am J Neuroradiol 2002; 23:1757-1766

Buijsen RA, Sellier C, Severijnen L-AW, et al. FMRpolyG-positive inclusions in CNS and non-CNS organs of a fragile $X$ premutation carrier with fragile $X$-associated tremor/ataxia syndrome. Acta Neuropathologica Communications. 2014;2:162.

Buijsen RA, Visser JA, Kramer P, Severijnen EA, Gearing M, CharletBerguerand N, Sherman SL, Berman RF, Willemsen R, Hukema RK. Presence of inclusions positive for polyglycine containing protein, FMRpolyG, indicates that repeat-associated non-AUG translation plays a role in fragile $X$-associated primary ovarian insufficiency. Hum Reprod. 2016;31(1):158-68.

Cantú JM, Scaglia HE, González-Diddi M, Hernández-Jáuregui $P$, Morato T, Moreno ME, Giner J, Alcántar A, Herrera D, Pérez-Palacios G. Inherited congenital normofunctional testicular hyperplasia and mental deficiency. A corroborative study. Hum Genet. 1978;41(3):331-9.

Capelli LP, Gonçalves MR, Leite CC, Barbosa ER, Nitrini R, ViannaMorgante AM. The fragile $\mathrm{X}$-associated tremor and ataxia syndrome (FXTAS).Arq Neuropsiquiatr. 2010;68(50):791-8.

Chang MC, Decaro JJ, Zheng M, Gearing M, Shubeck L, Sherman SL, Welt CK. Ovarian histopathological and ubiquitin-immunophenotypic features in fragile X-associated primary ovarian insufficiency: a study of five cases and selected controls. Histopathology 2011;59:1018-1023

Chen M, Zhao M, Lee CG, Chong SS. Identification of microsatellite markers $<1 \mathrm{Mb}$ from the FMR1 CGG repeat and development of a singletube tetradecaplex PCR panel of highly polymorphic markers for preimplantation genetic diagnosis of fragile X syndrome. Genet Med. 2016.

Chonchaiya W, Nguyen D, Au J, et al. Clinical involvement in daughters of men with fragile $\mathrm{X}$-associated tremor ataxia syndrome. Clinical genetics. 2010;78(1):38-46.

Cleary JD, Ranum LP. Repeat-associated non-ATG (RAN) translation in neurological disease. Hum Mol Genet. 2013;22(R1):R45-51.

Coffey SM, Cook K, Tartaglia N, et al. Expanded Clinical Phenotype of Women With the FMR1 Premutation. American journal of medical genetics Part A. 2008;146A(8):1009-1016. 
Collins SC, Bray SM, Suhl JA, et al. Identification of novel FMR1 variants by massively parallel sequencing in developmentally delayed males. Am J Med Genet A. 2010a;10:2512-2520.

Collins SC, Coffee B, Benke PJ, et al. Array-based FMR1 sequencing and deletion analysis in patients with a fragile $X$ syndrome-like phenotype. PLoS One. 2010b;5:e9476.

Cordeiro L, Abucayan F, Hagerman R, Tassone F, Hessl D. Anxiety disorders in fragile $X$ premutation carriers: Preliminary characterization of probands and non-probands. Intractable \& Rare Diseases Research. 2015;4(3):123-130.

Cornish K, Kogan C, Turk J, Manly T, James N, Mills A, Dalton A. The emerging fragile $X$ premutation phenotype: evidence from the domain of social cognition. Brain Cogn. 2005;57(1):53-60.

Crawford DC, Zhang F, Wilson B, Warren ST, Sherman SL. Fragile X CGG repeat structures among African-Americans: identification of a novel factor responsible for repeat instability. Hum Mol Genet. 2000;9(12):1759-69.

Cronister A, Schreiner R, Wittenberger M, Amiri K, Harris K, Hagerman RJ. Heterozygous fragile $X$ female: historical, physical, cognitive, and cytogenetic features. Am J Med Genet. 1991;38(2-3):269-74.

Darnell JC, Van Driesche SJ, Zhang C, Hung KY, Mele A, Fraser CE, Stone EF, Chen C, Fak JJ, Chi SW, Licatalosi DD, Richter JD, Darnell RB. FMRP stalls ribosomal translocation on mRNAs linked to synaptic function and autism. Cell. 2011;146(2):247-61.

De Boulle K, Verkerk AJ, Reyniers E, Vits L, Hendrickx J, Van Roy B, Van den Bos F, de Graaff E, Oostra BA, Willems PJ. A point mutation in the FMR-1 gene associated with fragile $X$ mental retardation. Nat Genet. 1993;3(1):31-5.

De Vries BB, Wiegers AM, Smits AP, et al. Mental status of females with an FMR1 gene full mutation. American Journal of Human Genetics. 1996;58(5):1025-1032.

Devys D1, Lutz Y, Rouyer N, Bellocq JP, Mandel JL. The FMR-1 protein is cytoplasmic, most abundant in neurons and appears normal in carriers of a fragile X premutation. Nat Genet. 1993;4(4):335-40.

Eberhart DE, Malter HE, Feng $Y$, Warren ST. The fragile $X$ mental retardation protein is a ribonucleoprotein containing both nuclear localization and nuclear export signals. Hum Mol Genet. 1996;5(8):108391

Edbauer D, Neilson JR, Foster KA, Wang CF, Seeburg DP, Batterton MN, Tada T, Dolan BM, Sharp PA, Sheng M. Regulation of synaptic 
structure and function by FMRP-associated microRNAs miR-125b and miR-132. Neuron. 2010;65(3):373-84.

Eichler EE, Holden JJ, Popovich BW, Reiss AL, Snow K, Thibodeau SN, Richards CS, Ward PA, Nelson DL. Length of uninterrupted CGG repeats determines instability in the FMR1 gene. Nat Genet. 1994;8(1):88-94

Escalante JA, Grunspun H, Frota-Pessoa O. Severe sex-linked mental retardation. J Génet Hum. 1971;19:137-140.

Escalante JA, Frota-Pessoa O. Retardamento mental. In: Genética Médica (Beçak W et al.), Savier, São Paulo,1973; 300-308

Farzin $F$, et al. Autism spectrum disorders and attentiondeficit/hyperactivity disorder in boys with the fragile $X$ premutation. J Dev Behav Pediatr. 2006;27(2 Suppl):S137-44.

Feng Y, Gutekunst CA, Eberhart DE, Yi H, Warren ST, Hersch SM. Fragile $\mathrm{X}$ mental retardation protein: nucleocytoplasmic shuttling and association with somatodendritic ribosomes. J Neurosci. 1997;17(5):1539-47.

Filipovic-Sadic S, Sah S, Chen L, Krosting J, Sekinger E, Zhang W, Hagerman PJ, Stenzel TT, Hadd AG, Latham GJ, Tassone F. A novel FMR1 PCR method for the routine detection of low abundance expanded alleles and full mutations in fragile $X$ syndrome. Clin Chem. 2010;56(3):399-408

Finucane B, Abrams L, Cronister A, Archibald AD, Bennett RL, McConkie-Rosell A. Genetic counseling and testing for FMR1 gene mutations: practice guidelines of the national society of genetic counselors. J Genet Couns. 2012;21(6):752-60. Erratum in: J Genet Couns. 2012;21(6):985.

Fraint A, Vittal P, Szewka A, Bernard B, Berry-Kravis E, Hall DA. New observations in the fragile X-associated tremor/ataxia syndrome (FXTAS) phenotype. Frontiers in Genetics. 2014;5:365.

Fryns JP, Dereymaeker A, Hoefnagels M, Volcke P, Van den Berghe $\mathrm{H}$. Partial $\operatorname{fra}(X)$ phenotype with megalotestes in fra $(X)$-negative patients with acquired lesions of the central nervous system. Am J Med Genet. 1986;23(1-2):213-9.

Gacy AM, Goellner G, Juranić N, Macura S, McMurray CT. Trinucleotide repeats that expand in human disease form hairpin structures in vitro. Cell. 1995;81(4):533-40.

Garber KB, Visootsak J,Warren ST. Fragile X syndrome. Eur. J. Hum. Genet. 2008;16:666-72 
Gessert S, Bugner V, Tecza A, Pinker M, Kühl M. FMR1/FXR1 and the miRNA pathway are required for eye and neural crest development. Dev Biol. 2010;341(1):222-35.

Giraud F, Ayme S, Mattei JF, Mattei MG. Constitutional chromosomal breakage. Hum Genet. 1976;34(2):125-36.

Gonçalves MR, Capelli LP, Nitrini R, Barbosa ER, Porto CS, Lucato LT, Vianna-Morgante AM. Atypical clinical course of FXTAS: rapidly progressive dementia as the major symptom. Neurology. 2007 May 22;68(21):1864-6.

Greco CM, et al. Neuronal intranuclear inclusions in a new cerebellar tremor/ataxia syndrome among fragile X carriers. Brain. 2002;125(Pt 8):1760-71.

Greco CM, et al. Clinical and neuropathologic findings in a woman with the FMR1 premutation and multiple sclerosis. Arch. Neurol 2008; 65: 1114-1116.

Grønskov K1, Brøndum-Nielsen K, Dedic A, Hjalgrim H. A nonsense mutation in FMR1 causing fragile X syndrome. Eur J Hum Genet. 2011 19(4):489-91

Hagerman RJ, Jackson C, Amiri K, Silverman AC, O'Connor R, Sobesky W. Girls with fragile $X$ syndrome: physical and neurocognitive status and outcome. Pediatrics. 1992;89(3):395-400.

Hagerman RJ, Hull CE, Safanda JF, Carpenter I, Staley LW, O'Connor RA, Seydel C, Mazzocco MM, Snow K, Thibodeau SN, et al. High functioning fragile $X$ males: demonstration of an unmethylated fully expanded FMR-1 mutation associated with protein expression. Am J Med Genet. 1994;51(4):298-308.

Hagerman RJ, Leehey $M$, Heinrichs $W$, et al. Intention tremor, parkinsonism, and generalized brain atrophy in male carriers of fragile $\mathrm{X}$. Neurology 2001;57:127-130.

Hagerman RJ. Physical and Behavioral Phenotype. In: Hagerman RJ, Hagerman PJ. Fragile $X$ Syndrome - Diagnosis, Treatment and Research. 3rd ed. Blatimore: John Hopkins University Press; 2002. pp.3109.

Hagerman RJ, et al. Fragile-X-associated tremor/ataxia syndrome (FXTAS) in females with the FMR1 premutation. Am J Hum Genet. 2004;74(5):1051-6.

Hagerman PJ, Hagerman RJ. Fragile X-associated tremor/ataxia syndrome-an older face of the fragile $X$ gene. Nat Clin Pract Neurol. 2007a Feb;3(2):107-12. 
Hagerman RJ, et al. Neuropathy as a presenting feature in fragile Xassociated tremor/ataxia syndrome. Am $J$ Med Genet A. 2007b;143A(19):2256-60.

Hagerman PJ. Current Gaps in Understanding the Molecular Basis of FXTAS. Tremor Other Hyperkinet Mov (N Y). 2012;2.

Hagerman R, Hagerman P. Advances in clinical and molecular understanding of the FMR1 premutation and fragile $\mathrm{X}$-associated tremor/ataxia syndrome. Lancet Neurol. 2013;12(8):786-98.

Hagerman RJ, Hagerman P. Fragile X-associated tremor/ataxia syndrome - features, mechanisms and management. Nat Rev Neurol. 2016;12(7):403-12.

Hall DA, Howard K, Hagerman R, Leehey MA. Parkinsonism in FMR1 premutation carriers may be indistinguishable from Parkinson disease. Parkinsonism \& related disorders. 2009;15(2):156-159.

Hall DA, O'keefe JA. Fragile X-associated tremor ataxia syndrome: the expanding clinical picture, pathophysiology, epidemiology, and update on treatment. Tremor Other Hyperkinet Mov 2012a;2:467-79.

Hall, Deborah et al. "Fragile X-Associated Tremor Ataxia Syndrome in FMR1 Gray Zone Allele Carriers." Movement disorders : official journal of the Movement Disorder Society 27.2 2012b; 296-300.

Hall DA, Birch RC, Anheim M, et al. Emerging topics in FXTAS. J Neurodev Disord 2014;6:31.

Hall D, Todorova-Koteva K, Pandya S, et al. Neurological and Endocrine Phenotypes of Fragile $X$ Carrier Women. Clinical genetics. 2016;89(1):60-67.

Hamlin A, Liu Y, Nguyen DV, Tassone F, Zhang L, Hagerman RJ. 2011. Sleep Apnea in Fragile X Premutation Carriers With and Without FXTAS. Am J Med Genet Part B 2011; 156:923-928.

Hamlin AA, Sukharev D, Campos L, Mu Y, Tassone F, Hessl D, Nguyen DV, Loesch D, Hagerman RJ. Hypertension in FMR1 premutation males with and without fragile X-associated tremor/ataxia syndrome (FXTAS). Am J Med Genet A. 2012; 158A(6):1304-9.

Harris SW, Hessl D, Goodlin-Jones B, Ferranti J, Bacalman S, Barbato I, et al. Autism profiles of males with fragile $X$ syndrome. Am J Ment Retard. 2008;113(6):427-38.

Harvey J, Judge C, Wiener S. Familial X-linked mental retardation with an $X$ chromosome abnormality. Journal of Medical Genetics. 1977;14(1):46-50. 
Heitz, D., Devys, D., Imbert, G., Kretz, C. and Mandel, J. L. Inheritance of the fragile $X$ syndrome: size of the fragile $X$ premutation is a major determinant of the transition to full mutation. J Med Genet. 1992;29 , 794-801.

Hessl, D. et al. Abnormal elevation of FMR1 mRNA is associated with psychological symptoms in individuals with the fragile $X$ premutation. Am. J. Med. Genet. B Neuropsychiatr. Genet. 2005;139B , 115-121.

Hinds HL, Ashley CT, Sutcliffe JS, Nelson DL, Warren ST, et al. Tissue specific expression of FMR-1 provides evidence for a functional role in fragile X syndrome. Nat. Genet. 1993;3:36-43

Howard-Peebles PN, Stoddard GR. Familial X-Linked Mental Retardation With a Marker X Chromosome and Its Relationship to Macro-Orchidism. Clin Genet 1980;17 (2):125-128.

Hunsaker MR, et al. Widespread non-central nervous system organ pathology in fragile $X$ premutation carriers with fragile $X$-associated tremor/ataxia syndrome and CGG knock-in mice. Acta Neuropathol. 2011;122(4):467-79 .

Hunter J, et al. Epidemiology of fragile $X$ syndrome: a systematic review and meta-analysis. Am J Med Genet A. 2014;164A(7):1648-58.

Jacky PB, Ahuja YR, Anyane-Yeboa K, Breg WR, Carpenter NJ, FrosterIskenius UG, Fryns JP, Glover TW, Gustavson KH, Hoegerman SF, et al. Guidelines for the preparation and analysis of the fragile $\mathrm{X}$ chromosome in lymphocytes. Am J Med Genet. 1991;38(2-3):400-3.

Jacquemont S, Hagerman RJ, Leehey $\mathrm{M}$, et al. Fragile X Premutation Tremor/Ataxia Syndrome: Molecular, Clinical, and Neuroimaging Correlates. American Journal of Human Genetics. 2003;72(4):869-878.

Jacquemont S, Farzin F, Hall D, Leehey M, Tassone F, et al. Aging in individuals with the FMR1 mutation. Am. J. Ment. Retard. 2004a;109:154-64

Jacquemont S, Hagerman RJ, Leehey MA et al. Penetrance of the fragile $\mathrm{X}$-associated tremor/ataxia syndrome in a premutation carrier population. JAMA 2004b; 291: 460-469.

Jacquemont $S$, et al. Size bias of fragile $X$ premutation alleles in lateonset movement disorders. J Med Genet 2006; 43:804-809.

Kaufmann WE, Cohen S, Sun HT, Ho G. Molecular phenotype of fragile $X$ syndrome: FMRP, FXRPs, and protein targets. Microsc Res Tech 2002;57:135-144.

Kunst CB e Warren ST. Cryptic and polar variation of the fragile $X$ repeat could result in predisposing normal alleles. Cell. 1994;77:853-861. 
Leehey MA, Legg W, Tassone F, Hagerman R. Fibromyalgia in fragile X mental retardation 1 gene premutation carriers. Rheumatology (Oxford). 2011;50(12):2233-6.

Lehrke R. Theory of X-linkage of major intellectual traits. Am J Ment Defic.1972;76(6):611-9.

Loesch DZ, Hay DA. Clinical features and reproductive patterns in fragile X female heterozygotes. J Med Genet. 1988;25(6):407-14.

Loesch DZ, Kotschet K, Trost N, et al. White matter changes in basis pontis in small expansion FMR1 allele carriers with parkinsonism. Am. J. Med. Genet. B. Neuropsychiatr. Genet. 2011;0(4):502-506.

Loesch DZ, Sherwell S, Kinsella G, Tassone F, Taylor A, Amor D, Sung $S$, Evans A. Fragile $X$-associated tremor/ataxia phenotype in a male carrier of unmethylated full mutation in the FMR1 gene. Clin Genet. 2012;82(1):88-92.

Loomis EW, et al. Transcription-associated R-loop formation across the human FMR1 CGG-repeat region. PLoS Genet. 2014;10(4):e1004294.

Lubs HA. A marker X chromosome. Am. J. Hum. Genet. 1969;21:231-44

Lugenbeel KA, Peier AM, Carson NL, Chudley AE, Nelson DL. Intragenic loss of function mutations demonstrate the primary role of FMR1 in fragile X syndrome. Nat Genet. 1995;10(4):483-5.

Maddalena A, Richards CS, McGinniss MJ, et al. Technical Standards and Guidelines for Fragile X: The First of a Series of Disease-Specific Supplements to the Standards and Guidelines for Clinical Genetics Laboratories of the American College of Medical Genetics. Genet Med. 2001;3(3):200-205.

Martin JP, Bell J. A Pedigree of Mental Defect Showing Sex-Linkage. Journal of Neurology and Psychiatry. 1943;6(3-4):154-157.

Martínez-Cerdeño V, et al. Fragile X-Associated Tremor/Ataxia Syndrome in a Man in His 30s. JAMA neurology. 2015;72(9):1070-1073.

Mingroni-Netto RC, Rosenberg C, Vianna-Morgante AM, Pavanello R de C. Fragile $X$ frequency in a mentally retarded population in Brazil. Am $\mathrm{J}$ Med Genet. 1990;35(1):22-7.

Monaghan KG, Lyon E, Spector EB. ACMG Standards and Guidelines for fragile $X$ testing: a revision to the disease-specific supplements to the Standards and Guidelines for Clinical Genetics Laboratories of the American College of Medical Genetics and Genomics. Genet Med. 2013;15(7):575-86.

Mothersead PK, Conrad K, Hagerman RJ, Greco CM, HessI D, Tassone F. GRAND ROUNDS: an atypical progressive dementia in a male carrier 
of the fragile $X$ premutation: an example of fragile $X$-associated tremor/ataxia syndrome. ApplNeuropsychol. 2005;12(3):169-78.

Murray A, Webb J, Grimley S, Conway G, Jacobs P. Studies of FRAXA and FRAXE in women with premature ovarian failure. J Med Genet. 1998;35(8):637-40.

Murray A, et al. Reproductive and Menstrual History of Females with Fragile $X$ Expansions. European journal of human genetics: EJHG 8.4 2000;247-252.

Muzar Z, Lozano R. Current research, diagnosis, and treatment of fragile $X$ - associated tremor/ataxia syndrome. Intractable Rare Dis Res 2014a;3:101-9.

Muzar, Zukhrofi et al. Addictive Substances May Induce a Rapid Neurological Deterioration in Fragile X-Associated Tremor Ataxia Syndrome: A Report of Two Cases. Intractable Rare Dis Res 2014b;3(4) 162-165.

Nolin SL, Brown WT, Glicksman A, et al. Expansion of the Fragile X CGG Repeat in Females with Premutation or Intermediate Alleles. American Journal of Human Genetics. 2003;72(2):454-464.

Nolin SL, Glicksman A, Ersalesi N, Dobkin C, Brown WT, Cao R, Blatt E, Sah S, Latham GJ, Hadd AG. Fragile X full mutation expansions are inhibited by one or more AGG interruptions in premutation carriers. Genet Med. 17(5):358-64, 2015

O'Donnell WT, Warren ST. A decade of molecular studies of fragile $X$ syndrome. Annu Rev Neurosci. 2002;25:315-38.

O'Dwyer JP, et al. Fragile X-associated tremor/ataxia syndrome presenting in a woman after chemotherapy. Neurology. 2005;65(2):331-2

Oberlé et al. Instability of a 550-base pair DNA segment and abnormal methylation in fragile X syndrome. Science. 1991;252:1097

Opitz JM, Segal AT, Klove H, Mathews C, Lehrke RL. X-linked mental retardation: Study of a large kindred with 20 affected members. J Pediatr 1965;67: 713-714.

Partington MW, Moore DY, Turner GM. Confirmation of early menopause in fragile X carriers. Am J Med Genet. 1996;64(2):370-2.

Pieretti M, Zhang FP, Fu YH, Warren ST, Oostra BA, Caskey CT, Nelson $\mathrm{DL}$. Absence of expression of the FMR-1 gene in fragile $\mathrm{X}$ syndrome. Cell. 1991;66(4):817-22.

Renpenning H, Gerrard JW, Zaleski WA, Tabata T. Familial Sex-Linked Mental Retardation. Canadian Medical Association Journal. 1962;87(18):954-956. 
Richards BW, Sylvester PE, Brooker C. Fragile X-linked mental retardation: the Martin-Bell syndrome. J Ment Defic Res. 1981;25 Pt 4:253-6.

Roberts JE, Bailey DB Jr, Mankowski J, Ford A, Sideris J, Weisenfeld LA, Heath TM, Golden RN. Mood and anxiety disorders in females with the FMR1 premutation. Am J Med Genet B Neuropsychiatr Genet. 2009;150B(1):130-9.

Rodriguez-Revenga L, Madrigal I, Pagonabarraga J, et al. Penetrance of FMR1 premutation associated pathologies in fragile $\mathrm{X}$ syndrome families. European Journal of Human Genetics. 2009;17(10):1359-1362.

Rogers C, Partington MW, Turner GM. Tremor, ataxia and dementia in older men may indicate a carrier of the fragile X syndrome. Clin Genet 2003; 64:54-56.

Roy D, Lieber MR. G clustering is important for the initiation of transcription-induced R-loops in vitro, whereas high $G$ density without clustering is sufficient thereafter. Mol Cell Biol. 2009;29(11):3124-33.

Santoro MR, Bray SM, Warren ST. Molecular mechanisms of fragile $X$ syndrome: a twenty-year perspective. Annu Rev Pathol. 2012;7:219-45.

Schneider A, Johnston C, Tassone F, Sansone S, Hagerman RJ, Ferrer E, Hessl D. Broad autism spectrum and obsessive-compulsive symptoms in adults with the fragile $X$ premutation. Clinical Neuropsychologist. 2016; 30(6), 929-943.

Schwartz CE, et al. Obstetrical and gynecological complications in fragile X carriers: a multicenter study. Am J Med Genet. 1994;51(4):400-2.

Sellier C, et al. Sequestration of DROSHA and DGCR8 by expanded CGG RNA repeats alters microRNA processing in fragile $X$-associated tremor/ataxia syndrome. Cell Rep. 2013;3(3):869-80 .

Seritan AL, Bourgeois JA, Schneider A, Mu Y, Hagerman RJ, Nguyen DV. Ages of Onset of Mood and Anxiety Disorders in Fragile $X$ Premutation Carriers. Current psychiatry reviews. 2013;9(1):65-71.

Sherman SL: Premature ovarian failure in the fragile $\mathrm{X}$ syndrome. Am J Med Genet 2000; 97: 189-194.

Sherman S, Pletcher BA, Driscoll DA. Fragile X syndrome: diagnostic and carrier testing. Genet Med. 2005;7(8):584-7.

Siomi H, Siomi MC, Nussbaum RL, Dreyfuss $\mathrm{G}$. The protein product of the fragile $\mathrm{X}$ gene, FMR1, has characteristics of an RNA-binding protein. Cell. 1993;74(2):291-8. 
Snow K, Tester DJ, Kruckeberg KE, Schaid DJ, Thibodeau SN. Sequence analysis of the fragile $X$ trinucleotide repeat: implications for the origin of the fragile X mutation. Hum Mol Genet. 1994;3(9):1543-51.

Snyder RD, Robinson A. Recessive sex-linked mental retardation in the absence of other recognizable abnormalities. Report of a family. Clin Pediatr (Phila).1969;8(11):669-74.

Sullivan AK, Marcus M, Epstein MP et al. Association of FMR1 repeat size with ovarian dysfunction. Hum Reprod 2005; 20: 402-412.

Summers SM, Cogswell J, Goodrich JE, et al. Prevalence of Restless Legs Syndrome and Sleep Quality in Carriers of the Fragile X Premutation. Clinical genetics. 2014;86(2):181-184.

Sutherland GR. Fragile sites on human chromosomes: demonstration of their dependence on the type of tissue culture medium. Science. 1977b;197(4300):265-6. PubMed PMID: 877551.

Sutherland GR. Marker $X$ chromosomes and mental retardation. N Engl J Med. 1977a;296(24):1415.

Sutherland GR, Ashforth PL. X-linked mental retardation with macroorchidism and the fragile site at Xq 27 or 28 . Hum Genet. 1979;48(1):117-20.

Tassone F, Hagerman RJ, Loesch DZ, Lachiewicz A, Taylor AK, Hagerman PJ. Fragile $X$ males with unmethylated, full mutation trinucleotide repeat expansions have elevated levels of FMR1 messenger RNA. Am J Med Genet. 2000a;94(3):232-6.

Tassone F, Hagerman RJ, Taylor AK, Gane LW, Godfrey TE, Hagerman PJ. Elevated levels of FMR1 mRNA in carrier males: a new mechanism of involvement in the fragile-X syndrome. Am $J$ Hum Genet. 2000b;66(1):6-15.

Tassone $F$, et al. CGG repeat length correlates with age of onset of motor signs of the fragile X-associated tremor/ataxia syndrome (FXTAS). Am J Med Genet B Neuropsychiatr Genet. 2007;144B(4):566-9.

te Velde ER, Pearson PL. The variability of female reproductive ageing. Hum Reprod Update. 2002;8(2):141-54.

Timchenko L. Molecular mechanisms of muscle atrophy in myotonic dystrophies. Int J Biochem Cell Biol. 2013;45(10):2280-7.

Todd PK, et al. CGG repeat-associated translation mediates neurodegeneration in fragile $X$ tremor ataxia syndrome. Neuron. 2013 May 8;78(3):440-55. Epub 2013 Apr 18. Erratum in: Neuron. 2013;79(2):402. 
Turner G, Eastman C, Casey J, McLeay A, Procopis P, Turner B. Xlinked mental retardation associated with macro-orchidism. Journal of Medical Genetics. 1975;12(4):367-371.

Turner G, Till R, Daniel A. Marker X chromosomes, mental retardation and macro-orchidism. N Engl J Med. 1978;299(26):1472.

Verheij C1, et al. Characterization and localization of the FMR-1 gene product associated with fragile $X$ syndrome. Nature. 1993: 24;363(6431):722-4.

Verkerk AJMH, Pieretti M, Sutcliffe JS, Fu Y-H, Kuhl DPA, et al. Identification of a gene (FMR-1) containing a CGG repeat coincident with a breakpoint cluster region exhibiting length variation in fragile $X$ syndrome. Cell 1991;65:905-14

Vianna-Morgante AM, Armando I, Frota-Pessoa O. Escalante syndrome and the marker X chromosome. Am J Med Genet. 1982;12(2):237-40.

Vianna-Morgante AM, Costa SS, Pares AS, Verreschi IT. FRAXA permutation associated with premature ovarian failure. Am J Med Genet. 1996;64(2):373-5.

Vianna-Morgante AM, Costa SS, Pavanello RCM, Mingroni-Netto RC. Premature ovarian failure (POF) in Brazilian fragile $X$ carriers. Genet Mol Biol. 1999;22(4):471-4

Winarni TI, Chonchaiya W, Sumekar TA, et al. Immune-mediated Disorders among Women Carrier of Fragile X Premutation Alleles. American journal of medical genetics Part A. 2012;0(10):2473-2481.

Wöhrle D, Hennig I, Vogel W, Steinbach P. Mitotic stability of fragile X mutations in differentiated cells indicates early post-conceptional trinucleotide repeat expansion. Nat Genet 1993;4:140- 142.

Wöhrle D, Salat U, Hameister H, Vogel W, Steinbach P. Demethylation, Reactivation, and Destabilization of Human Fragile $X$ Full-Mutation Alleles in Mouse Embryocarcinoma Cells. American Journal of Human Genetics. 2001;69(3):504-515.

Yu et al. Fragile $\mathrm{X}$ genotype characterized by an unstable region of DNA. Science 1991;252:1179

Zeesman S, Zwaigenbaum L, Whelan DT, Hagerman RJ, Tassone F, Taylor SA.Paternal transmission of fragile X syndrome. Am J Med Genet A. $2004 ; 129 A(2): 184-9$.

Zhong N, Yang W, Dobkin C, Brown WT. Fragile X gene instability: anchoring AGGs and linked microsatellites. Am $J$ Hum Genet. 1995;57(2):351-61. 


\section{APÊNDICE}

\subsection{Apêndice A - Teste MoCA}

MONTREAL COGNITIVE ASSESSMENT (MOCA)
Versäo Experimental Brasileira
Nome:

Escolaridade Sexo:
Data de nascimento: 1,1

Data de avaliaçäo: Idade:
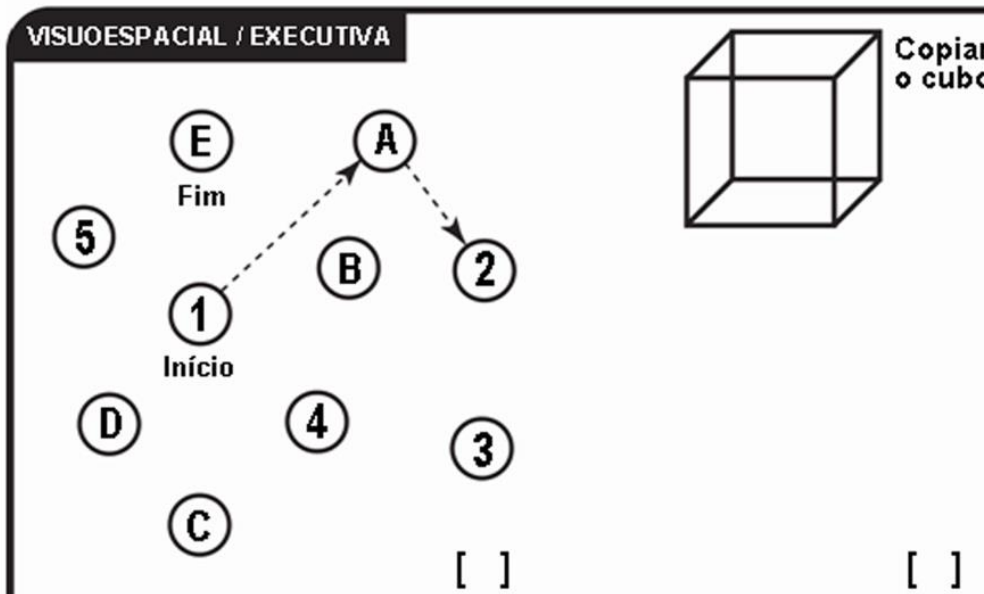

[ ]

[ ] [ ] [ ] [ ] 15

\section{NOMEAÇÄO}

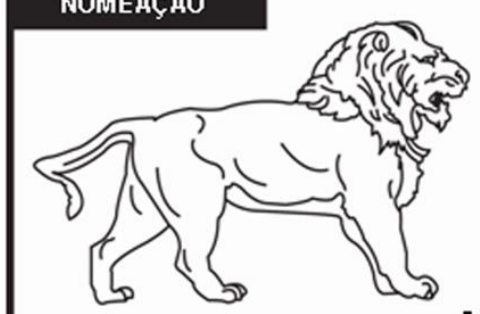

\section{[ ]}
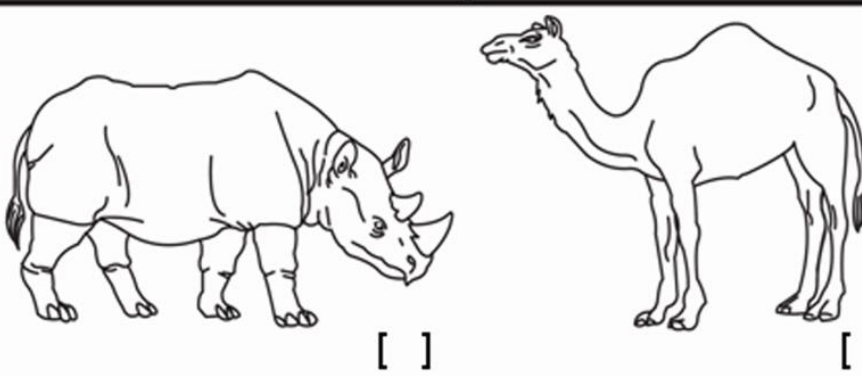

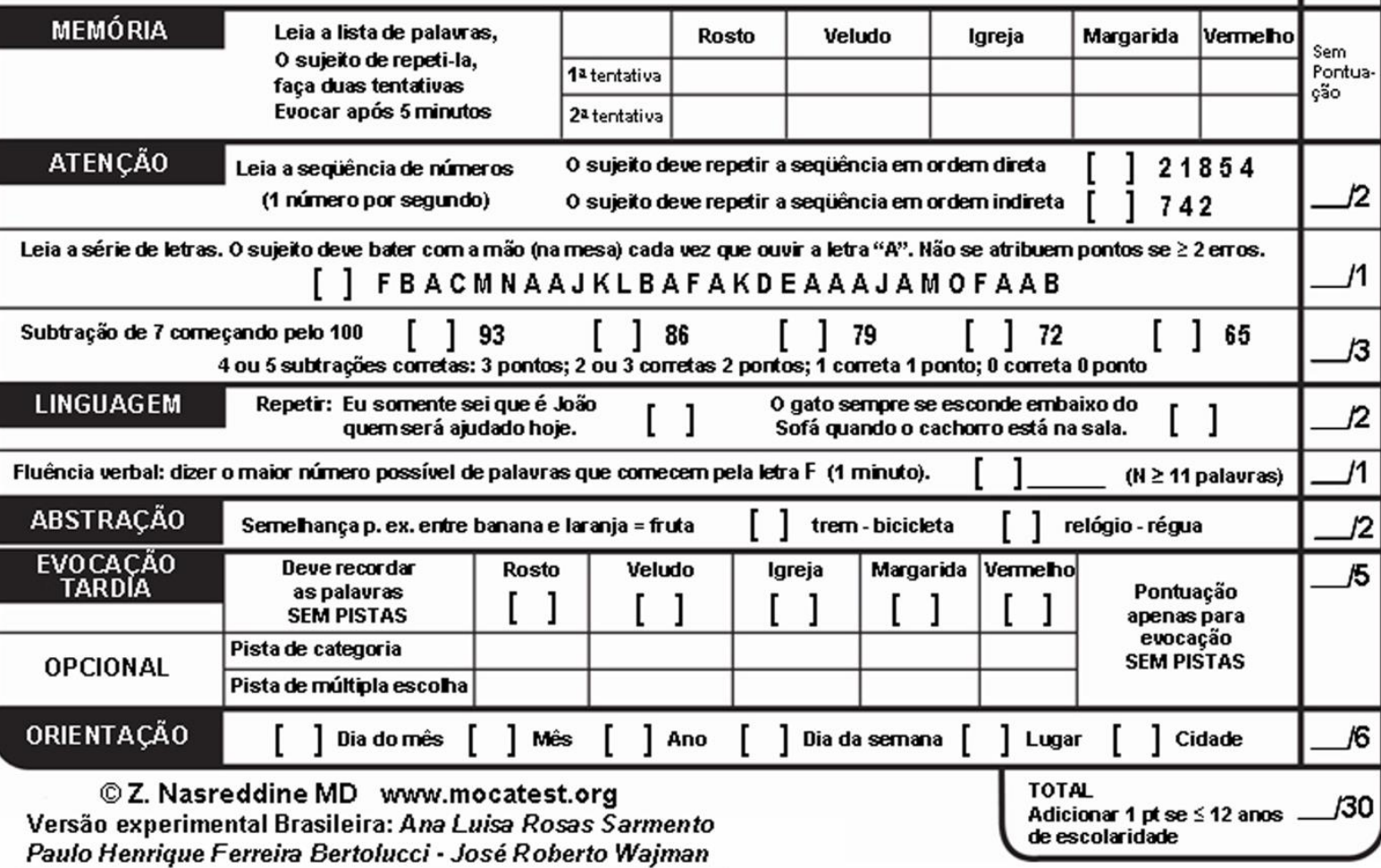

(UNIFESP-SP 2007) 